Article

\title{
The Impact of Multi-Projects on the Alteration of the Flow Regime in the Middle and Lower Course of the Hanjiang River, China
}

\author{
Xin Yin ${ }^{1,2}$, Jianyun Zhang ${ }^{1,2}$ and Jie Chen ${ }^{1,3, *}$ \\ 1 State Key Laboratory of Water Resources and Hydropower Engineering Science, Wuhan University, \\ Wuhan 430072, China; xiny@smail.nju.edu.cn (X.Y.); jyzhang@nhri.cn (J.Z.) \\ 2 State Key Laboratory of Hydrology-Water Resources and Hydraulic Engineering, \\ Nanjing Hydraulic Research Institute, Nanjing 210029, China \\ 3 Hubei Key Laboratory of Water System Science for Sponge City Construction, Wuhan University, \\ Wuhan 430072, China \\ * Correspondence: jiechen@whu.edu.cn
}

Received: 17 July 2020; Accepted: 14 August 2020; Published: 17 August 2020

\begin{abstract}
A large number of water resources development projects have significantly changed the natural flow regime of the middle and lower reaches of the Hanjiang River, especially the Danjiangkou Reservoir, cascade reservoirs, the South-to-North Water Diversion Middle Line Project and their compensation projects, completed in 1973, 2000, and 2014, respectively. The daily streamflow data of three stations in the middle and lower mainstream of the Hanjiang River are divided into four periods corresponding to pre-impact (1954-1973), interim (1974-1999), transition (2000-2013) and post-impact (2014-2018). Eco-flow metrics and indicators of hydrologic alteration (IHA) were used to study the change of natural flow regime. The annual streamflow decreased gradually during the four periods. The construction of the Danjiangkou Reservoir increased streamflow, minimum flow value, and the number of reversals in the dry season along the middle and lower course of the Hanjiang River. Moreover, the dam reduced streamflow, maximum flow value, low pulse duration, and the rise and fall rates in the wet season. Additionally, the streamflow reduced corresponding to the completion of cascade reservoirs and the Middle Route of South-to-North Water Diversion Project. In particular, the streamflow decreased drastically from July to September, affected by the Middle Route of the South-to-North Water Diversion Project. Furthermore, the compensation projects, such as the Yangtze-Hanjiang Water Diversion Project, mitigate the reduction of streamflow from July to September in the downstream. The study provides insights into the ecological and economic benefits associated with water resources development and use in the mainstream of the middle and lower course of the Hanjiang River for the achievement of sustainable development in the region.
\end{abstract}

Keywords: altertation of streamflow regime; multiple hydraulic engineering infrastructures; South-to-North Water Diversion; Danjiangkou Reservoir; Hanjiang River

\section{Introduction}

Rivers play a key regulatory function in maintaining the health and sustainability of ecological processes [1] and are essential to human well-being. The shortage of water resources due to uneven distribution poses a growing risk to the societies, economic developments, and ecosystems that rely on them. To relieve water scarcity, the majority of rivers are managed and regulated by dams and diversions constructed around the world, aiming to make full use of water resources, and for preventing flood and drought. However, the construction and operation of some projects have significantly altered the characteristic patterns of the rivers regarding quantity, timing, and variability of flow, 
temperature, or the transportation of sediments and nutrients [2-11], and have often led to impairment of eco-hydrologic system function and environmental degradation [12-15]. Assessment of the alteration degree of hydrologic characteristics is a fundamental and distinctive requirement for providing economic and social progress and for maintaining and restoring the main river ecological functions.

Valuation of changes in the flow characteristics is a determining factor because it helps decision-makers to manage the available resources more efficiently, especially when there are complex circumstances due to interlinked natural-social processes [16-18]. Numerous metrics have been proposed to evaluate the extent to which human activities have altered the hydrologic characteristics of rivers and quantify the influence of the implementation of hydraulic engineering projects. Among them, the method known as indicators of hydrologic alterations (IHA) has been applied worldwide with proven success [19-25]. The IHA consists of 32 parameters, initially, expanding to 33 parameters in follow-up research [20], which focus on variation in flows, considering the magnitude, duration, timing, frequency, and rate of water condition changes. The range of variability (RVA) approach was proposed by Richter [24], complementing the IHA method, suggesting that the 25 th and 75 th percentile range of indicators could be regarded as management targets based on natural flow.

Due to population growth and increasing economic activity around the world, the demands of water resources have also increased. Various hydraulic projects, including dams, reservoirs, and diversions, have been constructed along the rivers [12,26,27]. On the other hand, the regulation of the natural flow regime of the rivers is dominated by changing discharge, and connectivity fragmentation. This can strongly affect the structure and functioning of river ecosystems. In the case of China, some studies have evaluated the impacts on hydrologic alterations, emphasizing the influence of dams in some river basins [16-18,28,29]. In the Yangtze River, the largest river in China, more than 50,000 projects have been commissioned on the basin [30]. The Yangtze River represents the river in China most affected by flow regulation through impoundment, with severe social and environmental problems relative to the construction of projects. As for the largest tributary of the Yangtze River, the Hanjiang River, almost all types of projects have been constructed during the past decades. For instance, the Danjiangkou Reservoir (DJK), the Middle Route of South-to-North Water Diversion Project (MSNWDP), and the Yangtze-Hanjiang Water Diversion Project (YHWDP). To date, few attempts have been made to quantify the impacts of flow regulation associated with dam construction or channelization. Wang et al. [31] analyzed the flow regime along the Hanjiang River before and after the construction of the Danjiangkou Reservoir. Chen et al. [32] modeled the water quantity affected by four regulation scenarios given by engineering infrastructures with the long-term time series from 1956 to 1998 hydrologic data. The main gaps of previous studies were that engineering projects were not considered under real-world conditions. On the other hand, the impacts of the most recently implemented projects remain unknown to a great extent.

In this study, the objectives were: (1) the assessment of the changes in the flow regime caused by various hydraulic engineering infrastructures and their characteristics in three stations located along the mainstream of the middle and lower reaches of the Hanjiang River; and (2) the analysis of the impacts and the investigation of the potential causes in the flow changes in the river.

\section{Study Area and Data}

The Hanjiang River is the largest tributary of the Yangtze River in the subtropical monsoon climate zone of China. It has a length of $1577 \mathrm{~km}$ and a drainage area of 159,000 km², and flows through two provinces of China (Figure 1). The DJK is the key hydraulic engineering commissioned in 1973 across the river with a normal storage capacity of 17.4 billion $\mathrm{m}^{3}$, being increased to 29 billion $\mathrm{m}^{3}$ to serve as a source for the MSNWDP. The MSNWDP, one of the largest and longest water diversion projects in the world, started operation in 2014. The project intends to divert 9.5 billion $\mathrm{m}^{3}$ of water from DJK to Beijing City annually, spanning four provinces to solve water shortages in these areas. The YHWDP completed in 2014 to compensate water loss by the upstream project, namely in the 
MSNWDP. The target of the YHWDP is to divert 3.7 billion $\mathrm{m}^{3}$ of water from upstream of the Yangtze River to the Hanjiang River.

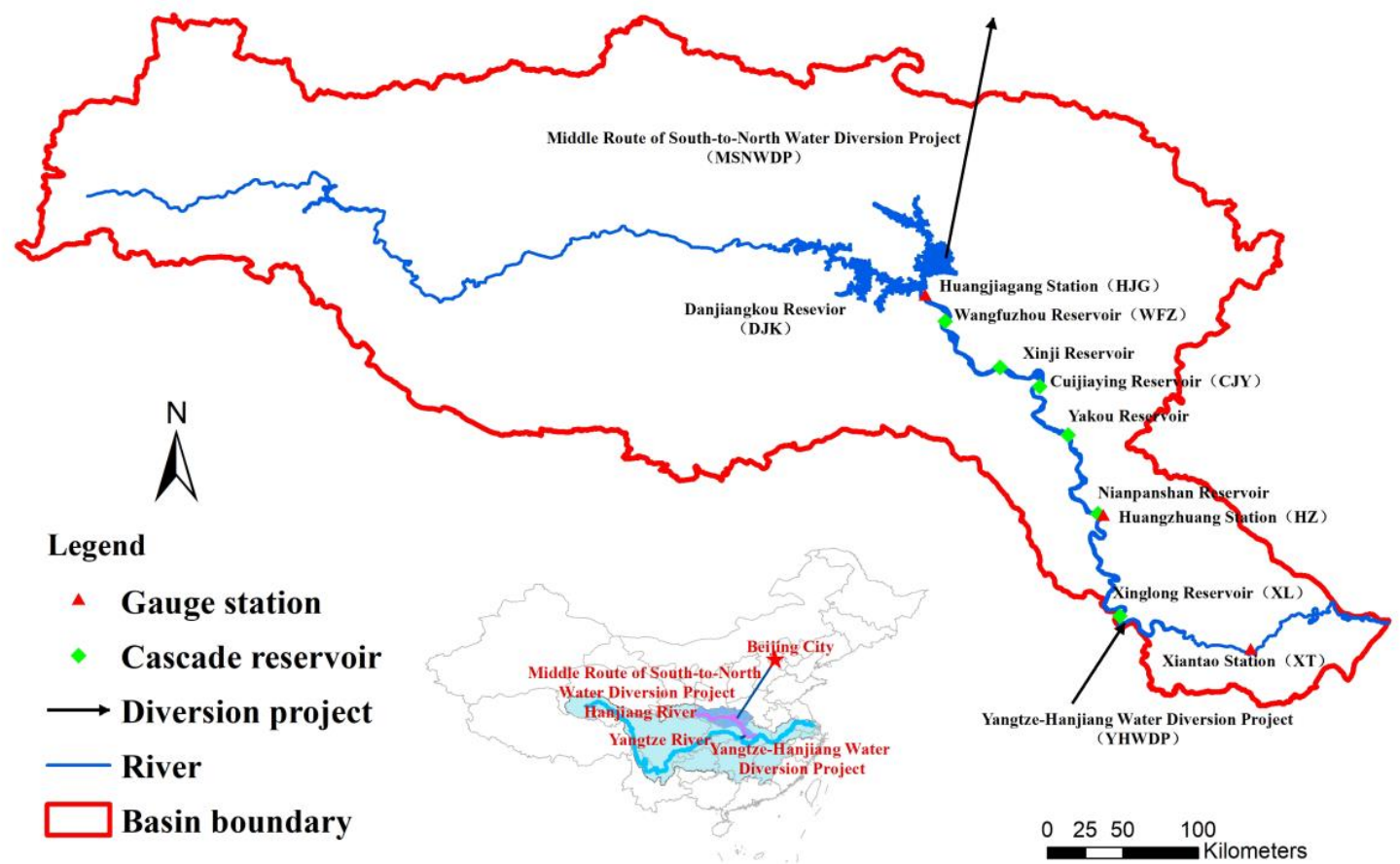

Figure 1. Location of projects and gauge stations in the mainstream of the middle-lower reaches of the Hanjiang river.

There are six cascade reservoirs located in the downstream of the DJK (Figure 1), half of them have been commissioned - Wangfuzhou (WFZ), Cuijiaying (CJY) and Xinglong (XL) - while the three others-Xinji, Yakou, and Nianpanshan-have still not been constructed. The characteristics of the main projects are shown in Table 1.

Table 1. Characteristics of the main projects in the Hanjiang river.

\begin{tabular}{ccc}
\hline Name & Commission Year & $\begin{array}{c}\text { Total Capacity } \\
\text { (billion } \mathbf{~ m}^{\mathbf{3}} \text { ) }\end{array}$ \\
\hline MSNDWP & 2014 & 9.50 \\
YHDWP & 2014 & 3.70 \\
Danjiangkou Reservoir & $(1973) 2013$ * & $(22.31) 33.91$ \\
Wangfuzhou Reservoir & 2000 & 0.31 \\
Xinji Reservoir & - & 0.44 \\
Cuijiaying Reservoir & 2010 & 0.25 \\
Yakou Reservoir & - & 0.70 \\
Nianpanshan Reservoir & - & 0.90 \\
Xinglong Reservoir & 2014 & 0.49 \\
\hline * Daniiangkou reservoir was commissioned in 1973, and it has
\end{tabular}

To estimate the impact of these projects on flow regime in the Hanjiang River, daily data were collected from three hydrologic gauge stations along the mainstream, including Huangiiagang (HJG), Huangzhuang (HZ) and Xiantao (XT), obtained from the Yangtze River Conservancy Commission of the Ministry of Water Resources (Figure 1). 


\section{Methods}

\subsection{Mann-Kendall Test}

The Mann-Kendall test, a rank-based non-parametric method, is widely used to detect the monotonic trends in hydrological time series $\left(x_{1}, x_{2}, x_{3}, \ldots x_{n}\right) . \mathrm{UF}_{k}$ and $\mathrm{UB}_{k}$ are two key statistical parameters. The cumulative number is set as $r_{i}$ when the sample $x_{i}$ is larger than $x_{j}(1 \leq j \leq i)$. The calculation formula of statistic $S_{k}$ is shown as follows:

$$
\begin{gathered}
r_{i}=\left\{\begin{array}{cc}
1 & x_{i}>x_{j} \\
0 & \text { else }
\end{array}\right\} j=1,2, \ldots, i \\
\mathrm{~S}_{k}=\sum_{i=1}^{k} r_{i}(2 \leq k \leq n)
\end{gathered}
$$

The mean and variance of the statistic $S_{k}$, which is assumed to be independent identically distributed, are shown as follows:

$$
\begin{gathered}
\mathrm{E}\left(\mathrm{S}_{k}\right)=k(k-1) / 4 \\
\operatorname{var}\left(\mathrm{S}_{k}\right)=k(k-1)(2 k+5) / 72
\end{gathered}
$$

The $\mathrm{UF}_{k}$ is defined as:

$$
\mathrm{UF}_{k}=\left(\mathrm{S}_{k}-\mathrm{E}\left(\mathrm{S}_{k}\right)\right) / \sqrt{\operatorname{var}\left(\mathrm{S}_{k}\right)}
$$

where $\mathrm{UF}_{k}$ is calculated by forwarding sequence, and $\mathrm{UB}_{k}$ is obtained by the same process with a reversed time series. When the intersection point of $\mathrm{UF}_{k}$ and $\mathrm{UB}_{k}$ is located within the confidence interval, the point is a potential beginning of abrupt change. In this study, the significance level $\alpha=0.05$ was used, the statistic $U_{k}>1.96$ indicates a significant ascending trend, whereas the statistic $\mathrm{UF}_{k}<-1.96$ implies a significant descending trend [33,34].

\subsection{Indicators of Hydrologic Alteration}

The IHA method is widely used to characterize the natural flow regime and evaluate the human-induced alterations on river flow. The IHA contains 33 hydrologic parameters, which are classified into five groups (as shown in Table 2): (1) magnitude of monthly water conditions, (2) magnitude and duration of annual extreme water conditions, (3) timing of annual extreme water conditions, (4) frequency and duration of high and low pulses, and (5) rate and frequency of water condition changes [20]. In this study, the IHA method was selected to assess the changes of discharge due to the construction of multi-projects in the Hanjiang River.

HJG is located downstream of the DJK, the boundary of the upstream and midstream of the Hanjiang River, at a distance of $6 \mathrm{~km}$. The streamflow of HJG can be a good representative of the discharge from DJK. Daily data collected at HJG from 1954 to 2018 were used to estimate the alteration caused by the construction of DJK and the operation of MSNWDP, as well as the consistency with other stations. The record was divided into four sub-periods, i.e., the pre-impact period (1954-1973), the interim period (1974-1999), the transition period (2000-2013), and the post-impact period (2014-2018). HZ is located at the boundary between midstream and downstream of the Hanjiang River; the length of the hydrologic record at $\mathrm{HZ}$ is identical to HJG. Considering the construction of WFZ and CJY, the record was also divided into four sub-periods, similar to HZ. XT is the last hydrologic gauge station before the Hanjiang River flows into the Yangtze River; the hydrologic data was obtained from 1972 to 2018, since there is no historical series of previous data. Similarly, the data of XT was divided into three sub-periods to estimate the impact of WFZ, CJY, XL, MSNWDP and YHWDP on the Hanjiang River, respectively, in the interim period (1974-1999), the transition period (2000-2013) and the post-impact period (2014-2018). 
Table 2. Thirty-three Parameters of the indicators of hydrologic alterations.

\begin{tabular}{|c|c|c|}
\hline Category & \multicolumn{2}{|c|}{ Parameters } \\
\hline $\begin{array}{l}\text { Group 1: Magnitude of monthly } \\
\text { water conditions }\end{array}$ & $\begin{array}{l}\text { Mean flow in January } \\
\text { Mean flow in July } \\
\text { Mean flow in February } \\
\text { Mean flow in August } \\
\text { Mean flow in March } \\
\text { Mean flow in September }\end{array}$ & $\begin{array}{l}\text { Mean flow in April } \\
\text { Mean flow in October } \\
\text { Mean flow in May } \\
\text { Mean flow in November } \\
\text { Mean flow in June } \\
\text { Mean flow in December }\end{array}$ \\
\hline $\begin{array}{l}\text { Group 3: timing of annual } \\
\text { extreme water conditions }\end{array}$ & Date of 1-day maximum & Date of 1-day minimum \\
\hline $\begin{array}{l}\text { Group 5: rate and frequency of } \\
\text { water condition changes }\end{array}$ & $\begin{array}{c}\text { Rise rates: Mean of all positive differences } \\
\text { between consecutive daily values } \\
\text { Number of hydrologic reversals }\end{array}$ & $\begin{array}{l}\text { Fall rates: Mean of all negative differences } \\
\text { between consecutive daily values }\end{array}$ \\
\hline
\end{tabular}

* The base flow index is calculated using the ratio of the seven-day minimum flow to the annual mean flow.

\subsection{Eco-Flow Metrics}

Vogel et al. [35] proposed a non-dimensional eco-flow metric that contains ecodeficit and ecosurplus to reflect the overall loss or gain for the river in any period of interest, such as year, season and month, in order to make up for inadequate of a single measure. The flow duration curve (FDC) is a good metric for illustrating the overall hydrologic state of a river system, such that it has a long history in the field of hydrology, but the traditional definition of the FDC depends on the particular period of the data, leading to some criticism. A new nonparametric framework of FDC has been proposed to improve this defect of FDC, and provided new applications in some projects [36,37]. The eco-flow metric was based on the previous research by simplification of other indicators of hydrologic alteration, to assess hydrologic alteration caused by reservoirs and other forms of river regulation [21]. The ecodeficit and ecosuplus were computed by the flow duration curve (FDC), which was plotted by the ordered daily data, defined the discharges $Q_{i}$ arranged in descending order, with $Q_{1}$ being the largest value, as a function of their exceedance probability $p_{i}=i /(n+1)$, where $n$ is the daily flow and $i$ is the rank [35]. As shown in Figure 2, the blue line indicates the FDC of the river in a natural period without any regulation, while the orange line indicates the FDC of the river while being regulated. The ecodificit is defined as the area within both below the unregulated FDC and above the regulated FDC. On the contrary, the ecosurplus is defined as the area that is both above the unregulated FDC and below the regulated FDC. In this paper, the median seasonal FDCs of three stations were employed within the pre-impact period to be a reference for the natural flow regime. 


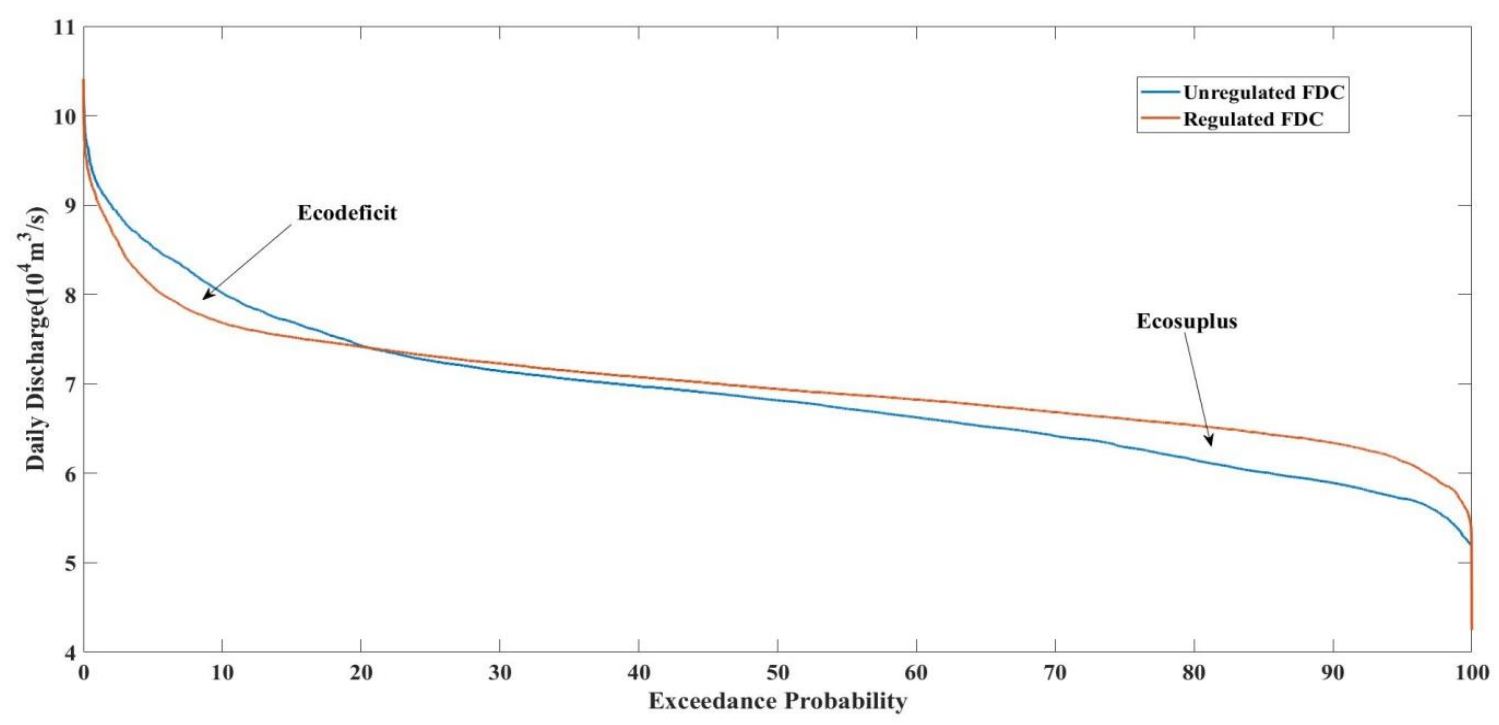

Figure 2. Definition of the ecodeficit and ecosurplus corresponding to the flow duration curves.

\section{Results}

In this study, the daily series data over a long-term period in three representative stations (HJG, $\mathrm{HZ}$, and XT) are employed to indicate the variation of discharge caused by different projects in the mainstream of the middle-lower reaches of Hanjiang River at different scales, including annual, seasonal and other characteristics of the flow regime.

\subsection{Analysis of Annual Discharge}

The statistics and trends of the annual discharge within four periods at the HJG, HZ and XT stations are shown in Figure 3. A similar trend of the mean annual discharge was observed at the three stations, decreasing over time with a fluctuation in the post-impact period.

The mean annual discharge at the HJG (Figure 3a) shows a slightly decreasing tendency in the interim period decreasing from $1229 \mathrm{~m}^{3} / \mathrm{s}$ to $1057 \mathrm{~m}^{3} / \mathrm{s}$ and a remarkable decreasing trend in the post-impact period from $1050 \mathrm{~m}^{3} / \mathrm{s}$ to $741 \mathrm{~m}^{3} / \mathrm{s}$. Additionally, no significant change was observed in the transition period compared with the interim period. The reduction of the mean annual discharge during the interim period had less impact on the volume of the water in the river due to the construction of DJK. This was aimed at improving the capacity of controlling the draught and flood for the downstream of Hanjiang River.

The markedly decreasing trend over the post-impact period was mainly caused by the operation of MSNWDP, which diverted water out of the Hanjiang River basin. The mean annual discharge both at HZ (Figure 3b) and XT (Figure 3c) had no conspicuous signs of change during the pre-impact and interim periods, despite the lack of data for XT, differing from HJG and proving that the impact of the construction of DJK on the farther downward stream gradually decreased. In the transition period, the mean annual discharge at $\mathrm{HZ}$ decreased from $1486 \mathrm{~m}^{3} / \mathrm{s}$ to $1393 \mathrm{~m}^{3} / \mathrm{s}$, while at XT decreased from $1273 \mathrm{~m}^{3} / \mathrm{s}$ to $1177 \mathrm{~m}^{3} / \mathrm{s}$. In comparison with HJG, the annual discharge was not strongly affected by WFZ and CJY through their storages and the release of impounded water. The annual discharge at HZ during the post-impact period fell from $1393 \mathrm{~m}^{3} / \mathrm{s}$ to $1038 \mathrm{~m}^{3} / \mathrm{s}$, similar to HJG. MSNWDP had a strong impact on the annual discharge in the streamflow. In comparison with $\mathrm{HJG}$ and $\mathrm{HZ}$, a lesser discharge at XT, dropped from $1177 \mathrm{~m}^{3} / \mathrm{s}$ to $919 \mathrm{~m}^{3} / \mathrm{s}$, was attributable to the joint effect of infrastructures in XL, YHWDP, and MSNWDP. This fact evidences that the compensation projects for MSNWDP, namely, YHWDP and cascade XL, had a compensatory function on the negative effect of discharge due to the MSNWDP. 

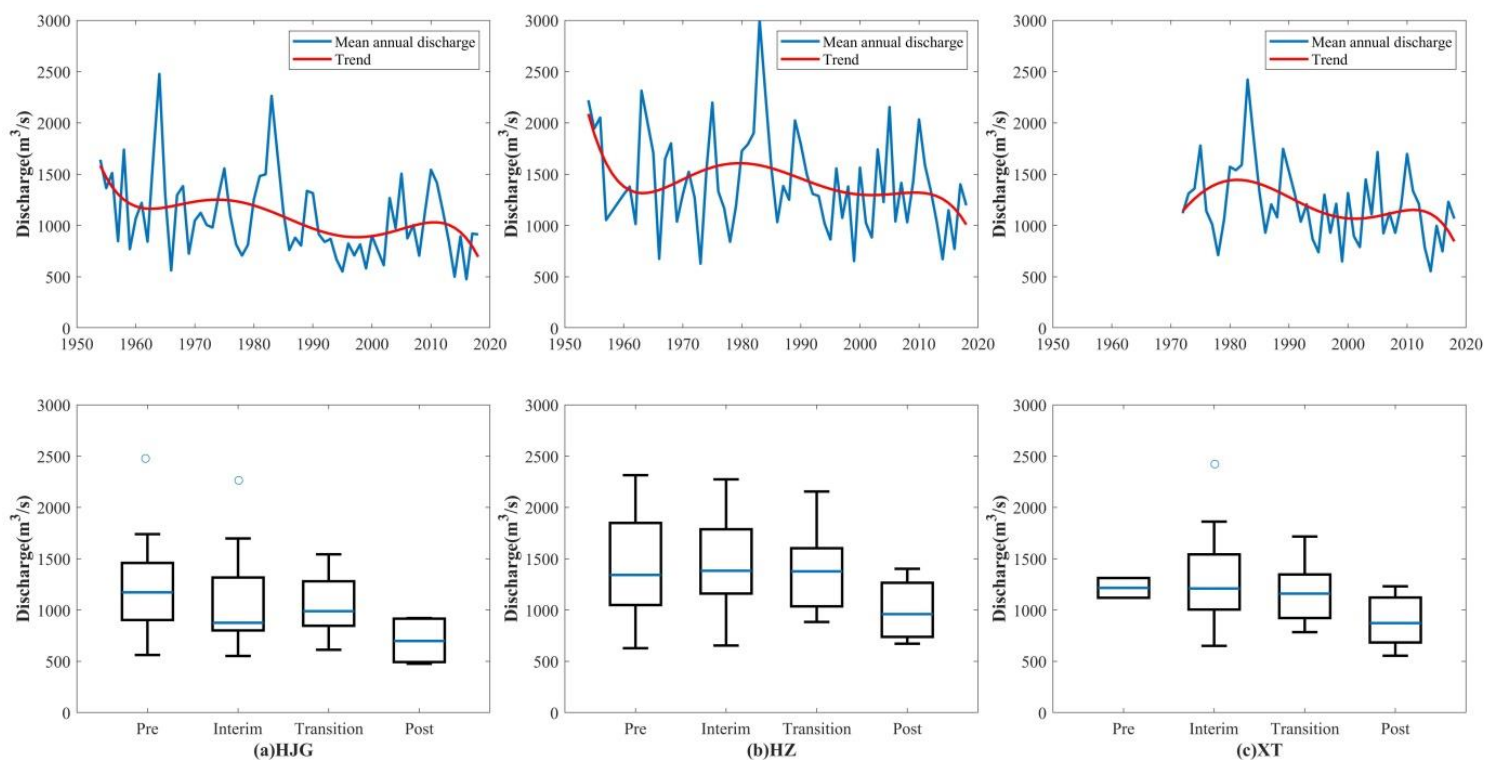

Figure 3. Mean annual discharge at three stations along the middle-lower reaches of the Hanjiang river.

In this study, the Mann-Kendall test was also applied to analyze the trends and abrupt points in the series of long-term data (Figure 4). The UF at HJG (Figure 4a) exhibits a descending trend after the intersection point when approaching the year 1974, with a transient fluctuation until 2018. However, there are no clear trends at $\mathrm{HZ}$ and $\mathrm{XT}$ that can be identified on the basis of the curves before the year 2010 (Figure 4b,c), while the UF curves imply decreasing trends after that, although the changes are not significant. The changes of the mean annual discharge at the stations are well-identified by the Mann-Kendall test, and they evidence the impact of multiple projects on the streamflow in the Hanjiang River.

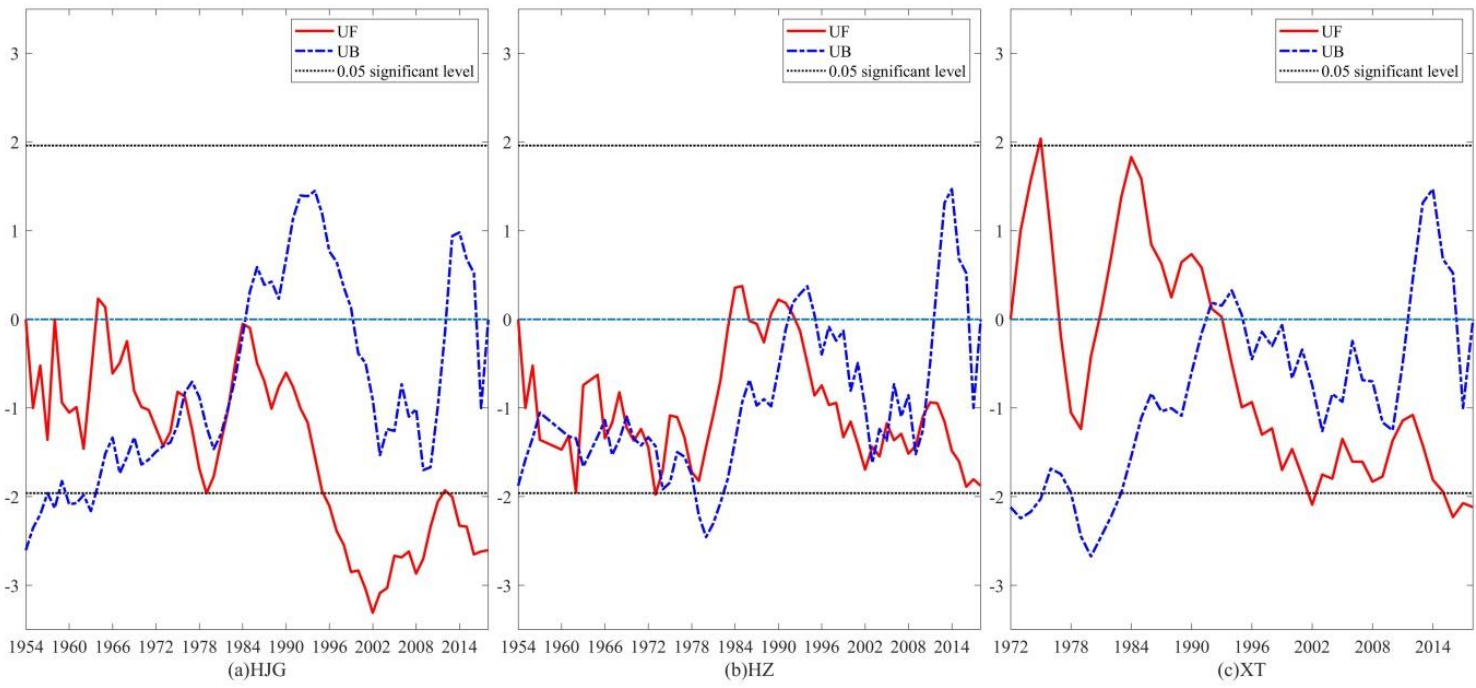

Figure 4. Mann-Kendall test for the annual discharge in three stations along the middle-lower reaches of the Hanjiang river.

\subsection{Analysis of Seasonal Discharge}

The streamflow was regulated by hydraulic infrastructures that store and release water during the wet and dry seasons, respectively, in order to provide multiple functions such as hydropower generation, water supply, and irrigation of crops. In the Hanjiang River basin, the wet season is from May to October and the dry season from November to April. Seasonal ecosurplus and ecodeficit values 
of streamflow in the stations are shown in Figures 5-7. The ecosurplus values show a similar trend both at HJG, HZ, and XT (Figure 5), while the amplitude of the variation at XT is smaller than HZ and HJG. During the dry seasons, the ecodeficit values were nearly zero after the construction of DJK at HJG and HZ. Nevertheless, the trend of ecodeficit value was descending at XT, and in a completely different respect to HJG and HZ. In the wet seasons, extremely low ecodeficit values emerged from the operation of the MSNWDP in the year 2014 for all of the stations, especially at XT (Figure 6).

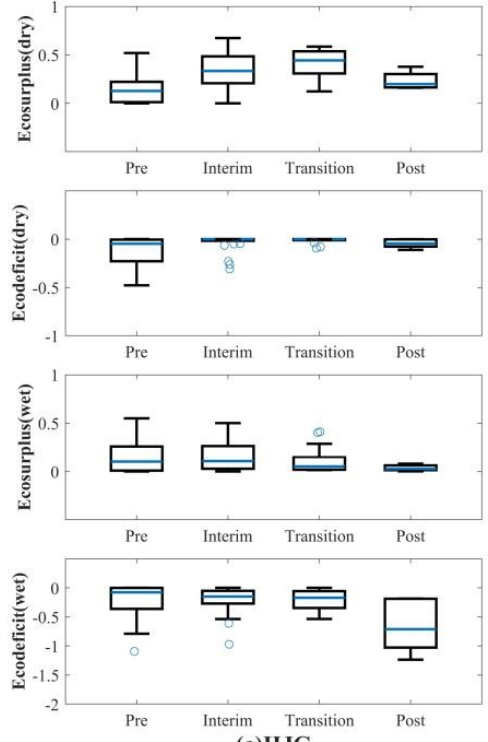

(a)HJG
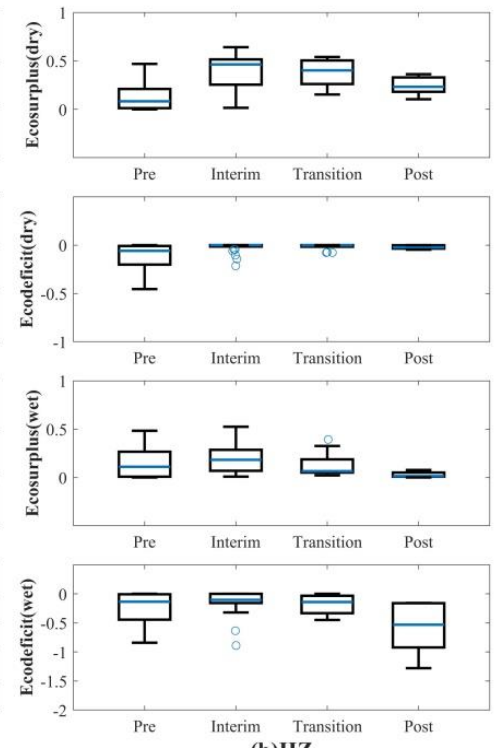

(b) $\mathrm{HZ}$
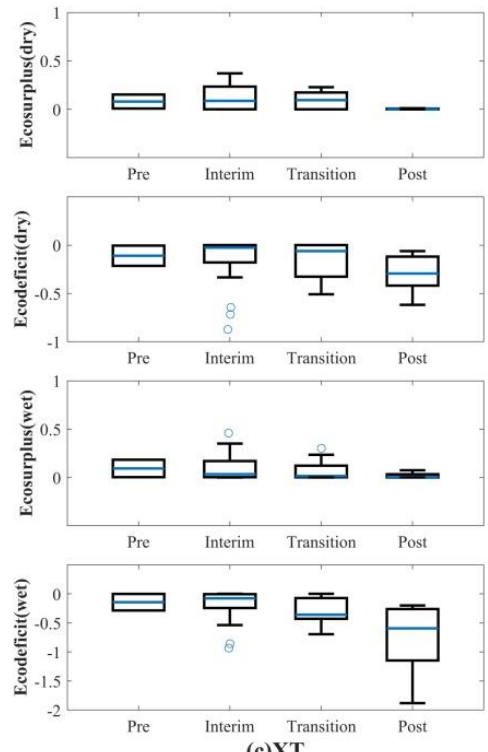

(c) XT

Figure 5. Boxplots of the seasonal ecosurplus and ecodeficit during four periods in the stations.
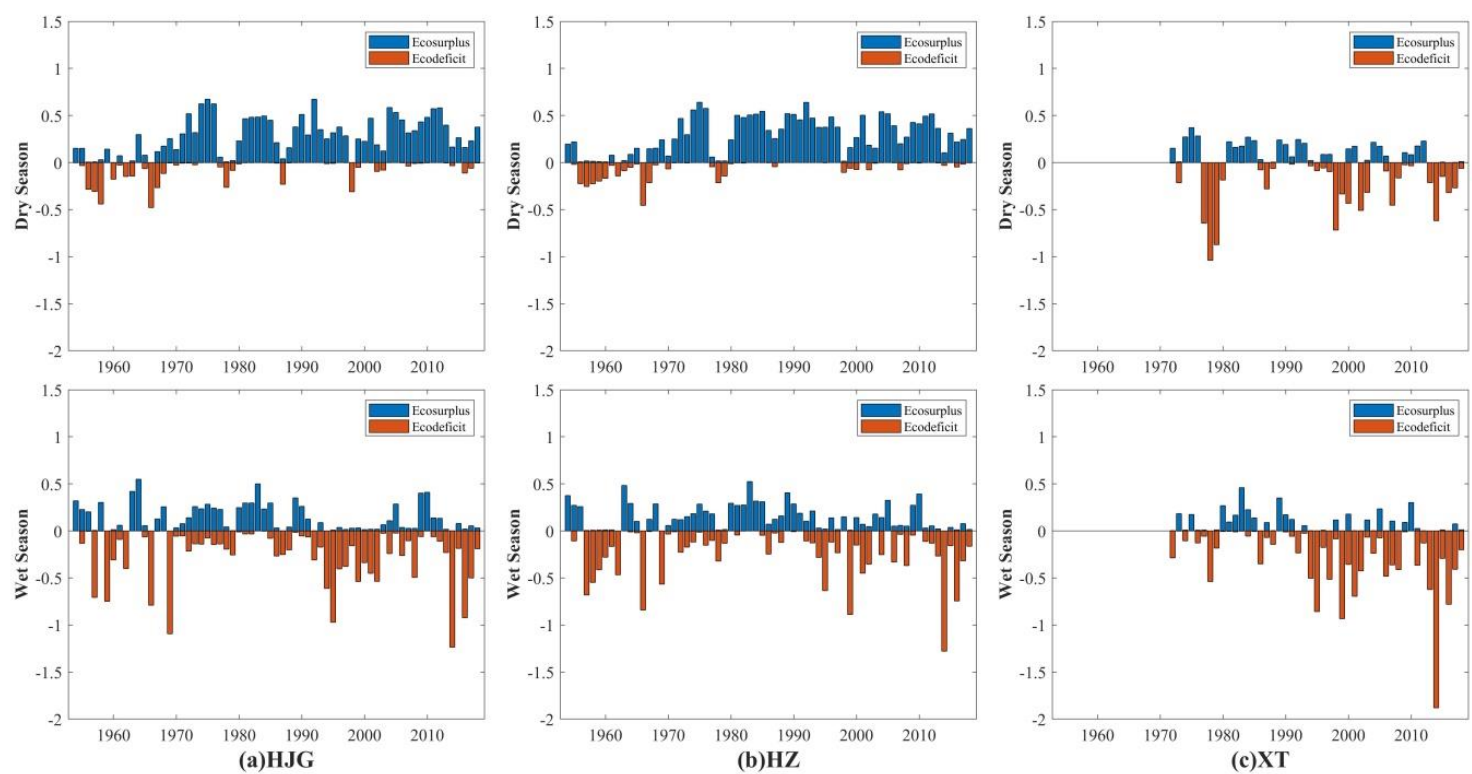

Figure 6. Changes of seasonal ecosurplus and ecodeficit in the stations.

In the dry seasons, the mean ecosurplus value was 0.14 at HJG during pre-impact period, and increased to 0.34 during the interim period due to the construction of DJK (Figure 7). However, with the construction of the MSNWDP, the value decreased to 0.24 , but within a normal range during the post-impact period, implying that there was a less negative impact associated with the project on runoff during the dry seasons. The mean value of ecodeficit was -0.13 during the pre-impact period, but it reached -0.04 and stayed stable in the subsequent two periods, evidencing the positive effect due to the dam on the streamflow during the dry seasons. In the post-impact period of dry seasons, 
the range of ecodeficit values underwent a minor increase due to the operation of the MSNWDP with less negative impact, as well as the ecosurplus values at HJG. In the wet seasons, the mean values of ecosurplus at HJG were 0.15 both during the pre-impact and interim periods, whereas the mean value was 0.04 in the post-impact period. The ecodeficit values were -0.24 and -0.21 during the pre-impact and interim periods, respectively, and this sharply changed to -0.61 during the post-impact period. Therefore, the construction of DJK had no impact on the ecosurplus and ecodeficit at HJG during the wet seasons.
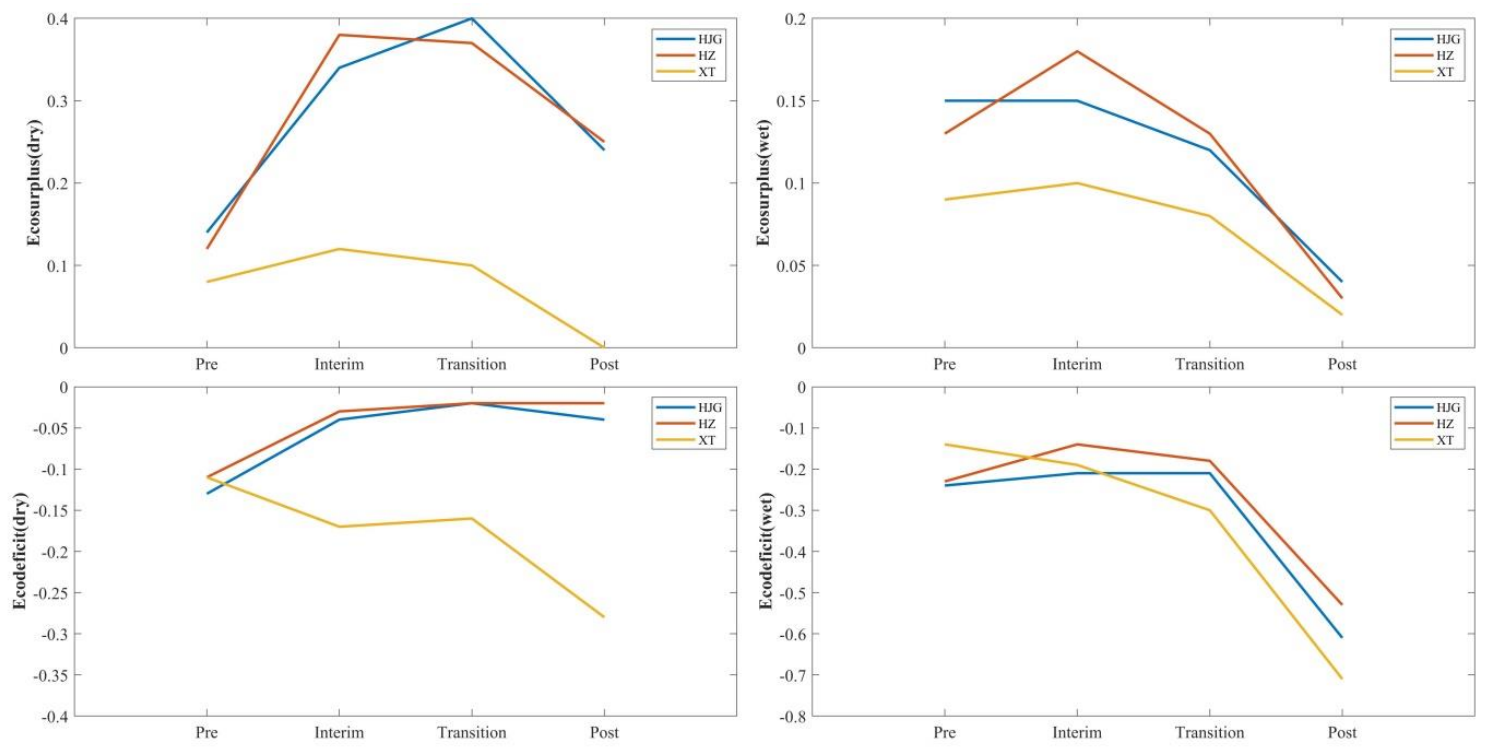

Figure 7. Mean values of seasonal ecosurplus and ecodeficit in the stations.

On the contrary, there was a negative impact on the streamflow in the post-impact period due to the operation of the MSNWDP. The range and mean eco-flow metric values were similar at HZ and HJG. In the dry seasons, the mean values of ecosurplus were $0.12,0.38,0.37$, and 0.25 during the four periods, respectively. The mean ecodeficit value was -0.11 during the pre-impact period, -0.03 within the interim period, and remained stable at -0.02 in the other two periods. In the wet seasons, the mean values of ecosurplus were $0.13,0.18,0.13$, and 0.03 in the four periods, respectively. The mean ecodeficit values were $-0.23,-0.14,-0.18$, and -0.53 for the different periods. Such records imply that the completion of DJK provided benefits to the discharge at HZ. However, in the transition and post-impact periods, the mean ecosurplus values decreased mainly owing to the constructions of WFZ and CJY, and to the operation of MSNWDP. The discharge into the river was negatively affected by the MSNWDP because of the lack of the total capacity of WFZ and CJY compared with MSNWDP.

During the dry seasons, the mean ecosurplus values were $0.08,0.12,0.1$, and 0 at XT for the four periods. The general trend of the values was similar to the observed at HJG and HZ. Nevertheless, the magnitude of increase at XT was rather smaller than those found at HJG and HZ from the pre-impact to interim periods, indicating that DJK has less positive function on the ecosurplus values at XT since they are far away from the mean. The mean ecodeficit values were $-0.11,-0.17,-0.16$, and -0.28 in the different periods. For the first two periods, the values dropped from -0.11 to -0.17 , indicating that the construction of DJK deteriorated the eco-hydrologic conditions at XT instead of favoring as in the cases of HJG and HZ. In the transition period, the change of ecodeficit at XT was the same as HZ, affected by WFZ and CJY, although the mean ecodeficit value, in the last period, decreased sharply from -0.16 to -0.28 with the operation of MSNWDP. The reservoirs XL and YHWDP should theoretically improve the eco-hydrological conditions at XT, but MSNWDP adversely affected them, making the positive function of $X \mathrm{~L}$ and $\mathrm{YHWDP}$, inoperative. In the wet season, the mean ecosurplus had a similar tendency as HJG and HZ with low values. The mean ecodeficit values gradually decreased from -0.14 
to -0.71 over the four periods. The completion of DJK improved the ecosurplus values at a certain level while the ecodeficit values worsened at XT.

Overall, the results of the eco-flow metrics for the middle and lower course of the Hanjiang River can be mainly attributed to the operations of DJK and MSNWDP, and the fact that streamflow is definitely reduced due to the MSNWDP, which supply water from DJK to Beijing City all the time. In the middle course of the Hanjiang River, the functions of the DJK, including flood control, hydropower generation, and navigation, decrease the discharge during the wet seasons while it is increased during the dry seasons, leading to changes in the seasonal flow based on the ecosurplus and ecodeficit values at HJG and HZ, from the pre-impact to interim periods. Conversely, the streamflow at $\mathrm{HZ}$ is reduced by the constructions of WFZ and CJY during the wet and dry seasons.

However, for the downstream of the Hanjiang River, the change caused by DJK in the streamflow differs from that found in the middle course. The main cause is the fact that water consumption has grown considerably with the urbanization of the area since the 1970s. Figure 8 shows the land-use map of the study area in 1990, 2005, and 2015, in which six first-level land-use types of the datasets were used, including cropland, forest, grass, water, urban, and unexploited land. The urban agglomeration in the downstream Hanjiang River is the core district of the middle and lower Hanjiang River, accounting for over half of the urban areas. These maps, for each year, represent the average state of land-use for three periods, including interim, transition, and post-impact. The urban areas of the lower Hanjiang River, in which XT is located covered $852 \mathrm{~km}^{2}$ in the year 1990, slightly increased to $889 \mathrm{~km}^{2}$ in 2005, and climbed to $1014 \mathrm{~km}^{2}$ in 2015. Although the urban areas in the downstream of Hanjiang River possess insufficient data before the 1970s, it is known that this area in the early times of China's foundation was much more backward than after the period of Reform and Opening-up (1970s). In other words, the urban areas of this region expanded rapidly after the 1970s. Therefore, the construction of DJK had a less positive impact on the streamflow at XT in terms of ecosurplus value, while also not avoiding the decrease in the ecodeficit value from the pre-impact to the interim period.
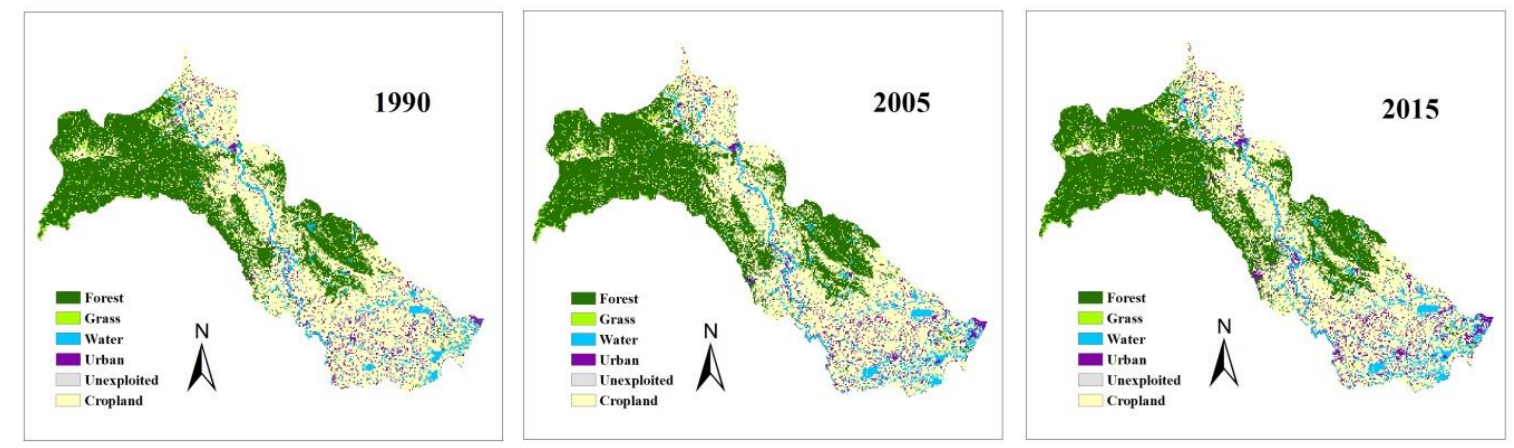

Figure 8. Land use map of the study area in 1990, 2005 and 2015. The dataset was obtained from the National Science \& Technology Infrastructure of China, National Earth System Science Data Sharing Infrastructure (http://www.geodata.cn).

\section{Discussion}

\subsection{Impact of $D J K$ on the Streamflow}

The changes in IHA indicators during the interim period (1974-1999) and pre-impact period (1954-1973) are shown in Table 3. The operation of DJK had a dramatic impact on the middle and lower Hanjiang River. At HJG and HZ, few alterations were observed for the 33 indicators studied, with changes less than $10 \%$ (only two indicators and six indicators, respectively) and with changes greater than $40 \%$ (13 indicators and 10 indicators, respectively). 
Table 3. Changes of IHA metrics in the interim period.

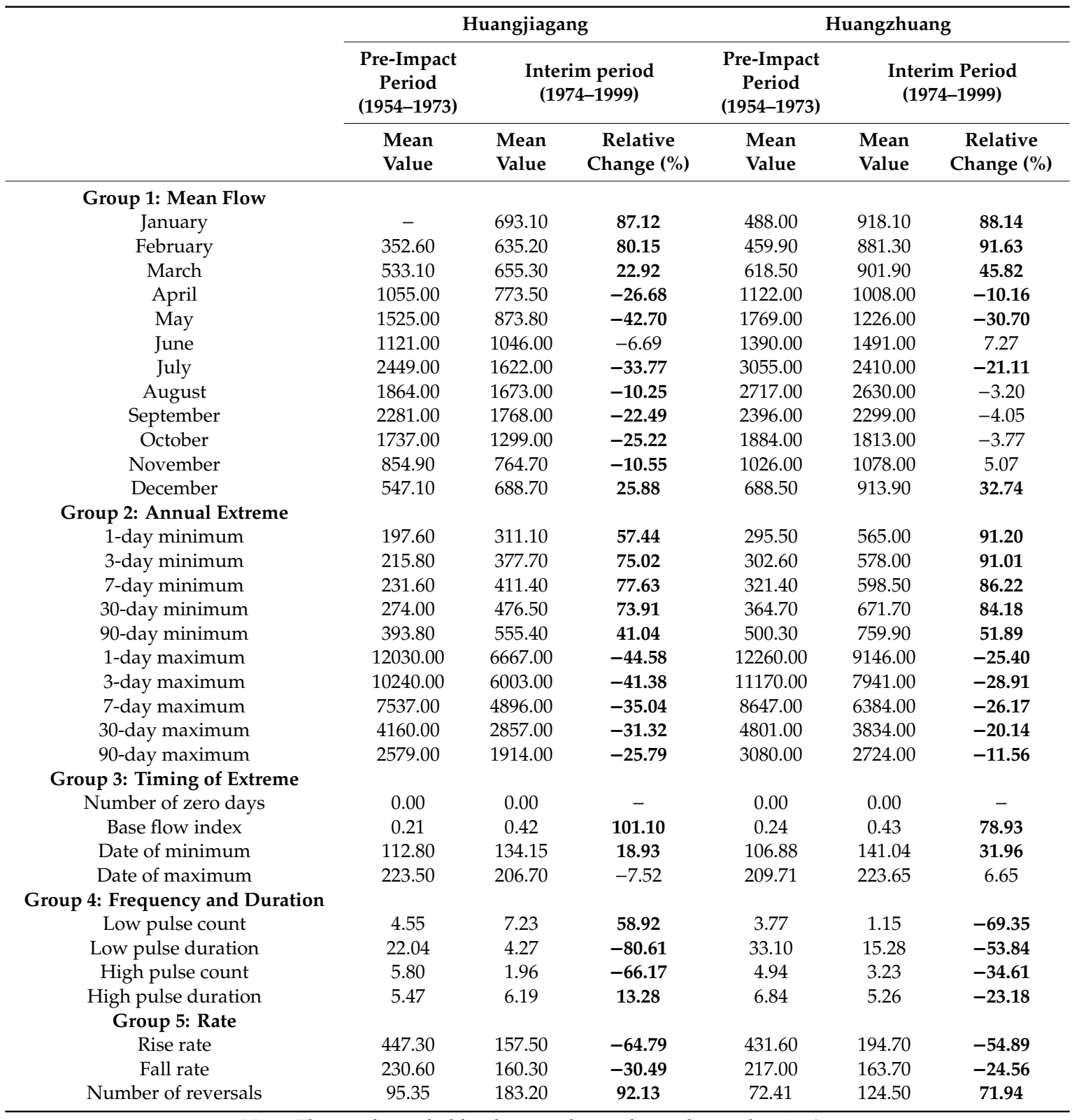

Note: The number in bold indicates relative change larger than $10 \%$.

It can be shown from Table 3 and Figure 9 that the construction of DJK changed the distribution of runoff within a year in the middle and lower Hanjiang River. The monthly variation of the average streamflow at HJG is higher than that at HZ, with a steady trend, indicating that the confluence is stable in the interval area. The variation of streamflow between HJG and HZ stabilizes at about 15\% except in January and December (Figure 9). This is the driest period in the middle and lower Hanjiang River, with a little confluence in the interval from HJG to HZ during December and January, when the runoff at HZ is almost dependent on the discharge of DJK. The relative change between HJG and HZ stayed within a narrow range, and the minimum of the change reaches $1.02 \%$ in January, indicating that the streamflow of the mainstream of the Hanjiang River comes mainly from the discharge from DJK during January. 


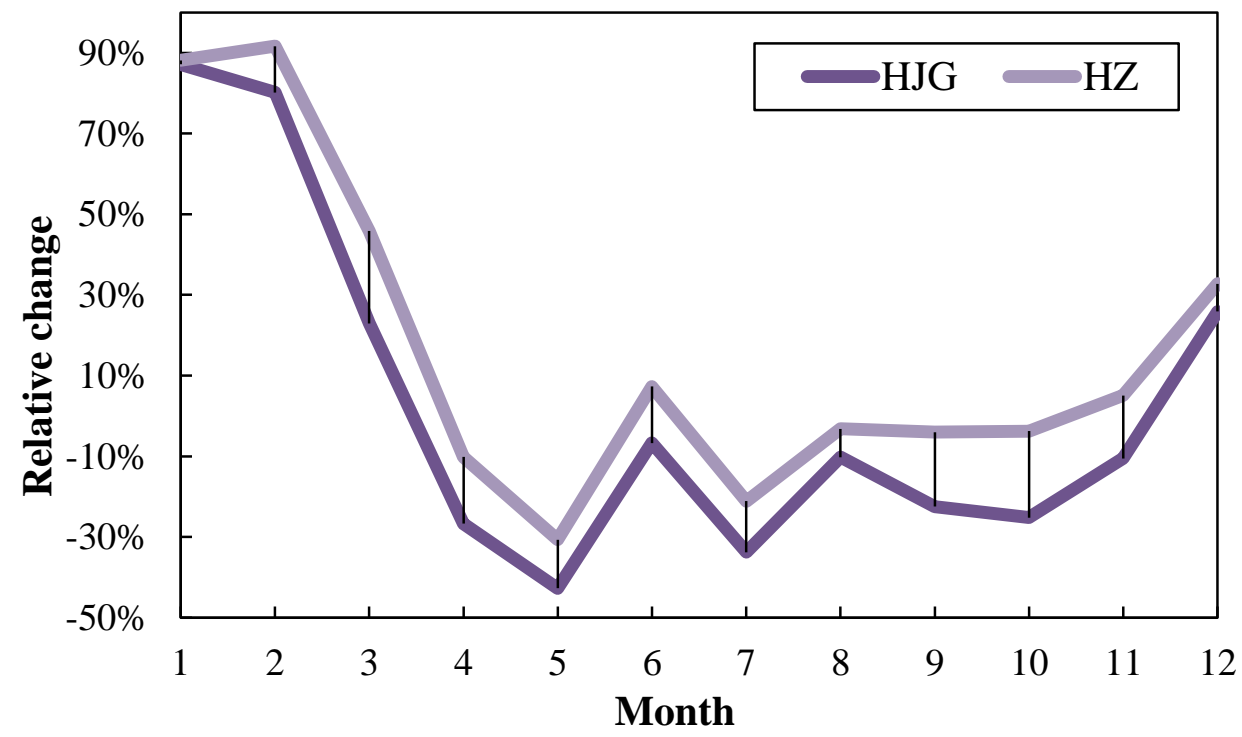

Figure 9. The relative change of monthly average flow at HJG and HZ between the interim and pre-impact periods.

The monthly average runoff at HJG and HZ increased significantly from December to March (Table 3). During January and February, the average streamflow at HJG and HZ increased by $87.12 \%$ and $91.63 \%$, respectively. At the beginning of the wet season, the DJK began to store water, resulting in a decrease in the average downstream flow, the streamflow reduction at HJG, and HZ achieved the highest value in May, up to $42.70 \%$ and $30.70 \%$, respectively. Therefore, DJK had a much greater impact on the downstream runoff during the dry season than the wet season.

As shown in Table 3, the variation of the minimum flow value at HJG and HZ increased significantly during the interim period compared to the pre-impact period. The 7-day minimum flow value at HJG changed substantially, decreasing up to $77.63 \%$, and the 1-day minimum flow value at $\mathrm{HZ}$ increased up to $91.20 \%$. On the contrary, the reduction of the maximum flow value at HJG and HZ was much lower than in the case of the minimum flow values. For example, the 7-day maximum flow value at HJG decreased by $35.04 \%$, and the 1-day maximum flow value at $\mathrm{HZ}$ decreased by $25.40 \%$, while other indicators had similar patterns.

The date corresponding to the minimum value at HJG was postponed from the 113th day to the 134th day, and from the 107th day to the 141th day in the case of HZ. The date for the maximum value at the two stations did not change significantly. The duration of the flow pulse mainly affects the flooding time of the floodplain and the spawning of floating fish. The duration of the high flow pulse at $\mathrm{HJG}$ and $\mathrm{HZ}$ is stable for 5-7 days. There is no clear change before and after the construction of DJK, while the low pulse duration changed significantly, from 22 days to 4 days, and from 33 days to 15 days at HJG and HZ, respectively. The rise and fall rates at HJG decreased by $64.79 \%$ and $30.49 \%$, respectively, during the interim period, and the number of reversals increased by $92.13 \%$. A similar pattern also appears at HZ, although with a lower variety than in the case of HJG.

The operation of DJK has greatly changed the natural flow regime in the middle and lower Hanjiang River. The annual distribution of runoff tends to be slight, the streamflow decreases during the wet season and increases during the dry season, which in turn, improves the capability of flood prevention and drought resistance. Furthermore, the project is of great benefit to other aspects, for example, for hydropower, the station of DJK has a total capacity of 900,000 KW, solving the power consumption of industry and agriculture in cities such as Wuhan City and Xiangyang City, Hubei Province. For navigation, the downstream river channel is navigable for 300-ton ships throughout the year, and the section from Xiangyang City to Wuhan City changed from seasonal navigation to year-round navigation, which greatly enhances the capacity of navigation. For water demand of agriculture, the area of arable land irrigated by water diversion through DJK exceeds $2400 \mathrm{~km}^{2}$, and the 
economic benefits outweigh 500 million yuan. At the same time, the changes in extreme values of runoff, for instance, the decrease in the maximum flow value, the delay in the date of maximum and the reduction in the rising rate, have a high impact on the reproduction of floating fish in the middle and lower Hanjiang River. In fact, the spawning volume of four major Chinese carps decreased from 900 to 93 million between the 1970s and the 2000s. In view of the above, the benefits and disadvantages given by the construction of DJK for the middle and lower Hanjiang River, the accent should be put on the need for comprehensive management favoring the coordination between water demand and sustainability of river ecosystems.

\subsection{Impact of WFZ and CJY on the Streamflow}

In the transition period (2000-2013), two cascade reservoirs were built in the mainstream of Hanjiang River, WFZ and CJY (Figure 1). The total storage capacity is shown in Table 1. Both reservoirs are located upstream of $\mathrm{HZ}$, and therefore, the changes in the IHA indicators corresponding to $\mathrm{HZ}$ and XT reflect the influence of the cascade reservoirs on the hydrological conditions of the middle and lower Hanjiang River during the transition period. As shown in Table 4, the impact of the construction of cascade reservoirs on streamflow is slight, with 13 and 10 indicators changing by more than $10 \%$ at $\mathrm{HZ}$ and XT, respectively.

In the transition period, the average discharge of $\mathrm{HZ}$ increased by $9.79 \%$ in September, while decreasing in other months. The average monthly streamflow decreased in May, June and October with a higher range, reaching values of $15.33 \%, 19.72 \%$, and $15.83 \%$, respectively. The major cause of the decline in streamflow for almost all of the year is the increase in water consumption primarily affected by the rapid development of urbanization, irrigation, and hydropower generation. The changing anomalies of discharge in May, June, September, and October are mainly influenced by the scheduling of cascade reservoirs. The runoff of downstream decreased by more than $10 \%$ during May and June, because the cascade reservoirs start to impound at the beginning of the wet season, increasing the efficiency of power generation. Due to the limited storage capacity of the cascade reservoirs, the runoff increased in September. At the end of the wet season, in October, the discharge is decreased to ensure the benefits of hydropower. Additionally, the runoff at XT had a similar change to HZ. In May, June, and October, runoff decreased by $10.83 \%, 18.78 \%$, and $17.86 \%$, respectively, and increased by $7.96 \%$ in September. In other months, the streamflow decreased to a great extent. Generally, the streamflow changes significantly at HZ and XT during May, June, September and October, associated with the degree of efficiency of hydropower generation during the transition period.

The maximum and minimum flow values at $\mathrm{HZ}$ and $\mathrm{XT}$ decreased within a similar range. The 1-day and 3-day maximum flow values at $\mathrm{HZ}$ were reduced by $17.08 \%$ and 11.22\%, respectively, while they were decreased by $14.75 \%$ and $11.49 \%$, respectively, at XT. The 90 -day minimum flow value decreased by $10.63 \%$. The date corresponding to the minimum value moved from 141th day to 193th day at HZ, and the date of maximum did not change significantly as well as the date of maximum and minimum at XT. Moreover, the low pulse duration at HZ was further reduced from 15 to 11 days. The variety of low pulse count, high pulse count and high pulse duration was slight compared to the pre-impact period and interim period. There was no low pulse at XT during the interim period and transition period, while the changes in high pulse count and high pulse duration were almost the same as those at $\mathrm{HZ}$. The rise and fall rates at $\mathrm{HZ}$ decreased by $23.78 \%$ and $26.70 \%$, respectively, during the transition period, and the number of reversals increased by $22.49 \%$, which is a smaller change compared to the interim period.

At XT, both the rise and fall rates decreased by $27.67 \%$ and $27.95 \%$, respectively, and there were no significant changes in the number of reversals. 
Table 4. Changes of IHA metrics in the transition period.

\begin{tabular}{|c|c|c|c|c|c|c|}
\hline & \multicolumn{3}{|c|}{ Huangzhuang } & \multicolumn{3}{|c|}{ Xiantao } \\
\hline & \multirow{2}{*}{$\begin{array}{c}\begin{array}{c}\text { Interim } \\
\text { Period } \\
(1974-1999)\end{array} \\
\text { Mean } \\
\text { Value }\end{array}$} & \multicolumn{2}{|c|}{$\begin{array}{c}\text { Transition Period } \\
\quad(2000-2013)\end{array}$} & \multirow{2}{*}{$\begin{array}{c}\begin{array}{c}\text { Interim } \\
\text { Period } \\
(1974-1999)\end{array} \\
\text { Mean } \\
\text { Value }\end{array}$} & \multicolumn{2}{|c|}{$\begin{array}{l}\text { Transition Period } \\
\quad(2000-2013)\end{array}$} \\
\hline & & $\begin{array}{l}\text { Mean } \\
\text { Value }\end{array}$ & $\begin{array}{c}\text { Relative } \\
\text { Change (\%) }\end{array}$ & & $\begin{array}{l}\text { Mean } \\
\text { Value }\end{array}$ & $\begin{array}{c}\text { Relative } \\
\text { Change (\%) }\end{array}$ \\
\hline \multicolumn{7}{|l|}{ Group 1: Mean Flow } \\
\hline January & 918.10 & 866.80 & -5.59 & 872.30 & 814.40 & -6.64 \\
\hline February & 881.30 & 838.20 & -4.89 & 832.90 & 796.10 & -4.42 \\
\hline March & 901.90 & 878.10 & -2.64 & 843.90 & 837.50 & -0.76 \\
\hline April & 1008.00 & 917.40 & -8.99 & 850.30 & 820.80 & -3.47 \\
\hline May & 1226.00 & 1038.00 & -15.33 & 1028.00 & 916.70 & -10.83 \\
\hline June & 1491.00 & 1197.00 & -19.72 & 1246.00 & 1012.00 & -18.78 \\
\hline July & 2410.00 & 2282.00 & -5.31 & 1974.00 & 1781.00 & -9.78 \\
\hline August & 2630.00 & 2584.00 & -1.75 & 2112.00 & 1954.00 & -7.48 \\
\hline September & 2299.00 & 2524.00 & 9.79 & 1885.00 & 2035.00 & 7.96 \\
\hline October & 1813.00 & 1526.00 & -15.83 & 1568.00 & 1288.00 & -17.86 \\
\hline November & 1078.00 & 1016.00 & -5.75 & 999.10 & 928.60 & -7.06 \\
\hline December & 913.90 & 887.80 & -2.86 & 864.80 & 814.60 & -5.80 \\
\hline \multicolumn{7}{|l|}{ Group 2: Annual Extreme } \\
\hline 1-day minimum & 565.00 & 519.50 & -8.05 & 495.10 & 475.10 & -4.04 \\
\hline 3-day minimum & 578.00 & 542.20 & -6.19 & 531.40 & 487.90 & -8.19 \\
\hline 7-day minimum & 598.50 & 563.10 & -5.91 & 556.10 & 508.90 & -8.49 \\
\hline 30-day minimum & 671.70 & 627.00 & -6.65 & 621.00 & 568.20 & -8.50 \\
\hline 90-day minimum & 759.90 & 701.30 & -7.71 & 701.70 & 627.10 & -10.63 \\
\hline 1-day maximum & 9146.00 & 7584.00 & -17.08 & 5985.00 & 5102.00 & -14.75 \\
\hline 3-day maximum & 7941.00 & 7050.00 & -11.22 & 5554.00 & 4916.00 & -11.49 \\
\hline 7-day maximum & 6384.00 & 5958.00 & -6.67 & 4773.00 & 4332.00 & -9.24 \\
\hline 30-day maximum & 3834.00 & 3795.00 & -1.02 & 3059.00 & 2925.00 & -4.38 \\
\hline 90-day maximum & 2724.00 & 2683.00 & -1.51 & 2206.00 & 2138.00 & -3.08 \\
\hline \multicolumn{7}{|c|}{ Group 3: Timing of Extreme } \\
\hline Number of zero days & 0.00 & 0.00 & - & 0.00 & 0.00 & - \\
\hline Base flow index & 0.43 & 0.43 & -0.65 & 0.46 & 0.45 & -2.78 \\
\hline Date of minimum & 141.04 & 193.21 & 36.99 & 139.38 & 144.50 & 3.67 \\
\hline Date of maximum & 223.65 & 213.93 & -4.35 & 232.35 & 215.43 & -7.28 \\
\hline \multicolumn{7}{|c|}{ Group 4: Frequency and Duration } \\
\hline Low pulse count & 1.15 & 3.00 & 159.97 & 0.00 & 0.00 & - \\
\hline Low pulse duration & 15.28 & 10.72 & -29.84 & - & - & - \\
\hline High pulse count & 3.23 & 2.29 & -29.25 & 3.35 & 2.36 & -29.56 \\
\hline High pulse duration & 5.26 & 8.23 & 56.46 & 7.44 & 10.48 & 40.92 \\
\hline \multicolumn{7}{|l|}{ Group 5: Rate } \\
\hline Rise rate & 194.70 & 148.40 & -23.78 & 124.10 & 89.76 & -27.67 \\
\hline Fall rate & 163.70 & 120.00 & -26.70 & 96.89 & 69.81 & -27.95 \\
\hline Number of reversals & 124.50 & 152.50 & 22.49 & 97.42 & 101.90 & 4.60 \\
\hline
\end{tabular}

Note: The number in bold means relative change is larger than $10 \%$.

Two cascade reservoirs were built during the transition period in the middle and lower Hanjiang River, both of them located in the area between DJK and HZ. Except for September, the average flow decreased to varying degrees, including the maximum and minimum flow value, indicating that the construction of cascade reservoirs has a continuous negative effect on the streamflow of the mainstream of Hanjiang River. The river's aquatic habitat was fragmented by the reservoirs, destroying fish spawning and migration channels, at the same time, the hydrological conditions, such as the maximum flow value, date of the maximum value and the rise rate were also affected. This was similar during the interim period, resulting in a high decrease of the spawning of four major Chinese carps from 93 to 3 million between the 2000s and the 2010s. The cascade reservoirs further improved human development efficiency and management capabilities in the middle and lower Hanjiang River, such as flood control and drought resisting and hydropower generation. The construction of two cascade reservoirs has further improved the navigation capacity of the river. WFZ can increase navigable ships from 300 to 500 tons, and CJY can increase navigable ships to 1000 tons. In addition, the annual power 
generation capacity of the two cascade reservoirs reached 950 million KWh, providing sufficient power for urban development in the basin. Although the negative impact of the cascade reservoirs on the ecological environment of the river is less than that of the DJK, it cannot be ignored, and joint dispatch with the DJK is needed to minimize the negative impacts.

\subsection{Impact of Water Diversion Projects and XL on the Streamflow}

During the post-impact period (2014-2018), the DJK was heightened, and the total storage capacity increased by 11.6 billion cubic meters, and at the same time, the MSNDWP was operative. According to the statistics of the Ministry of Water Resources of the People's Republic of China, the total water transfer volume exceeded 20 billion cubic meters by 2018. The compensation projects XL and YHDWP for the MSNDWP started to operate in 2014. The main function of $X \mathrm{~L}$ is to raise the water level in the reservoir area to ensure the water diversion and navigation conditions in the midstream. The YHDWP replenishes the downstream water volume, thus alleviating the negative impact caused by the MSNDWP, located between the HZ and XT (Figure 1). Table 5 and Figure 10 illustrate the changes in various indicators for the three stations during the post-impact period. At these three stations, the indicators decreased to 26, 23, and 23, respectively, indicating that the MSNDWP had further changed the hydrological regime in the middle and lower Hanjiang River.

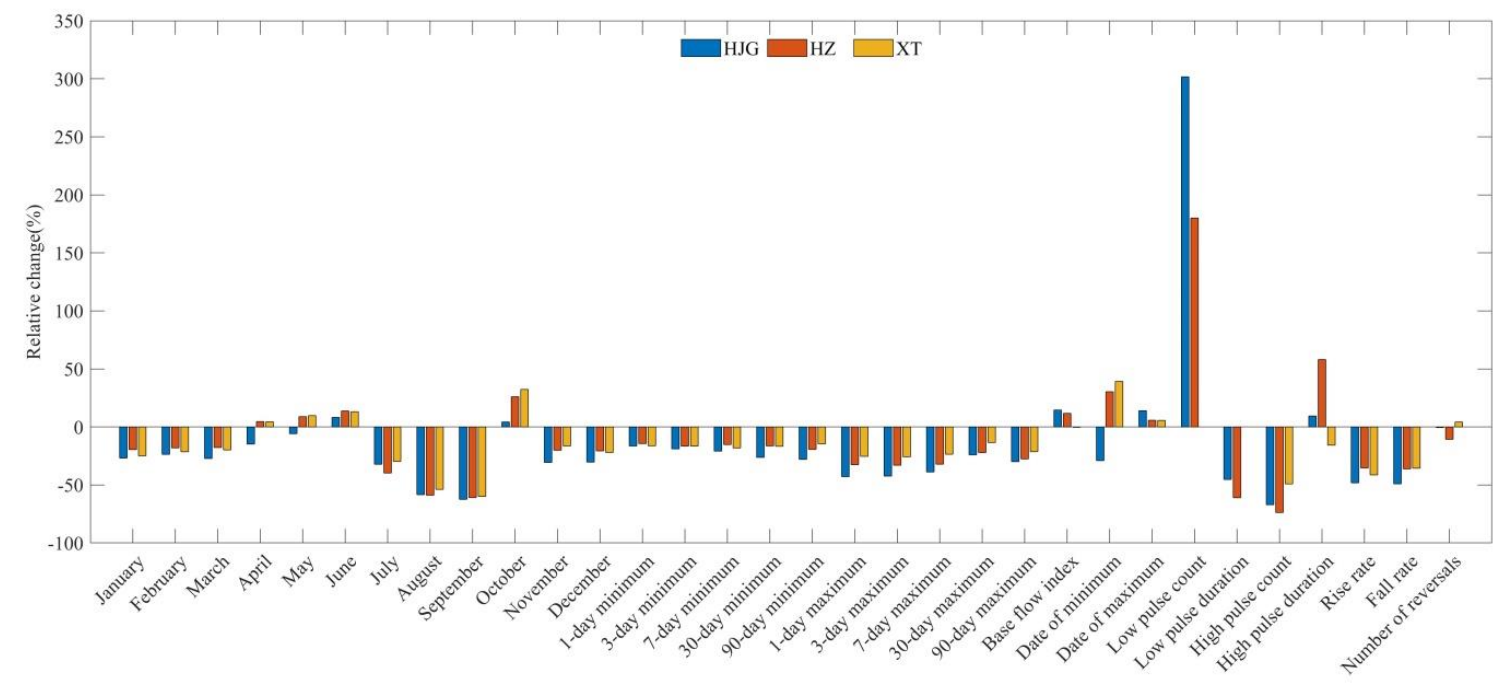

Figure 10. The relative change of 33 IHA indicators at HJG, HZ and XT between the transition and post-impact periods.

As shown in Figure 11, the results evidence the changing process of monthly average discharge of three stations during the post-impact period, the changing laws of which are highly similar. In the dry season, the flow at the downstream station is mainly affected by the discharge from DJK into the small catchment in the midstream of Hanjiang River. Therefore, the average flow reduction of three stations is almost stable at about $20 \%$ due to the effect of water transfer. The streamflow mainly occurs during the wet season from July to September and corresponds to the storage period of DJK in the Hanjiang River basin. The discharge at each station decreased to a great extent. The decreased magnitude of runoff at $\mathrm{HZ}$ is higher than others, and the average streamflow decreased by $1322 \mathrm{~m}^{3} / \mathrm{s}$ in the period, while the runoff at HJG and XT decreased by $859 \mathrm{~m}^{3} / \mathrm{s}$ and $934 \mathrm{~m}^{3} / \mathrm{s}$, respectively. 

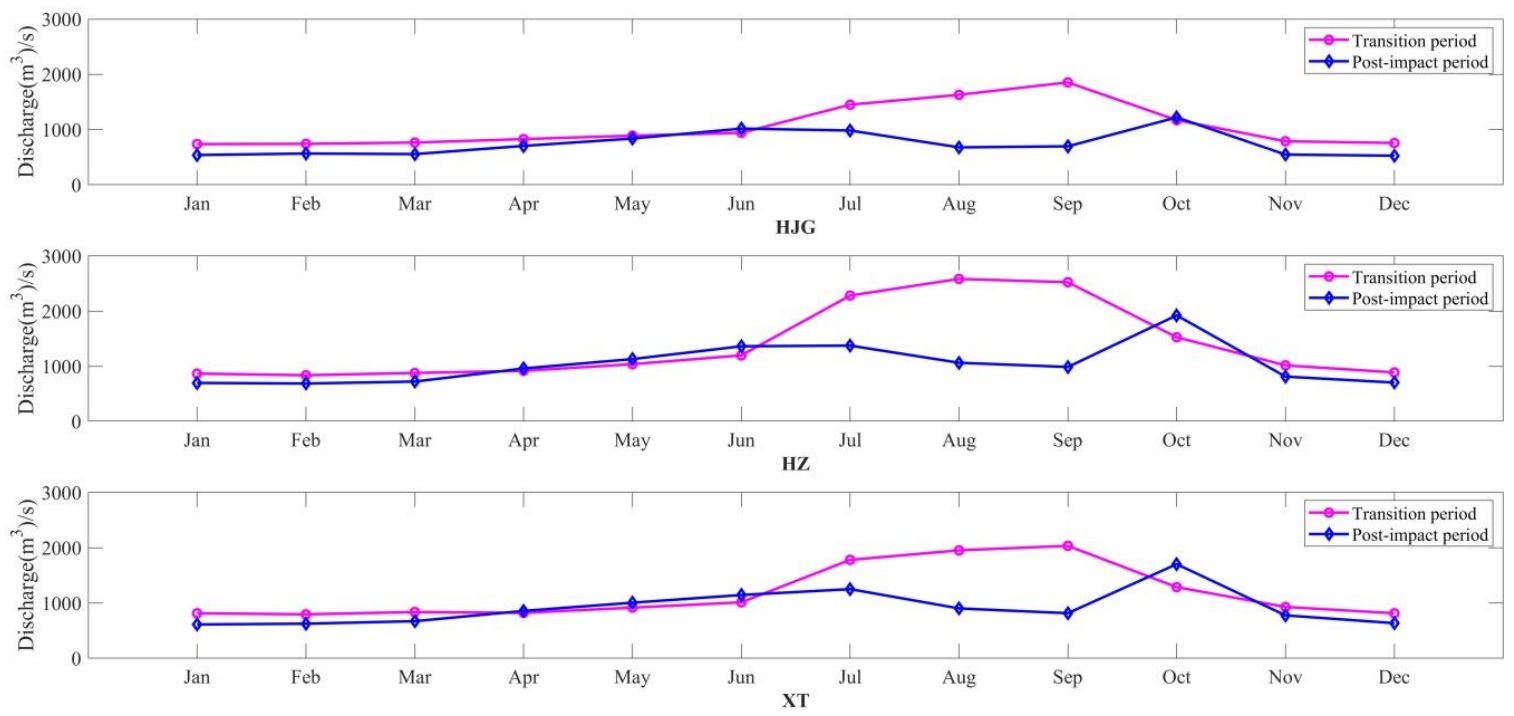

Figure 11. Average monthly flow at HJG, HZ and XT between the transition and post-impact periods.

As shown in Table 4, the average streamflow of HZ and XT did not change significantly from July to September during the interim and transition periods, indicating that the compensation projects of the MSNDWP play a key function in improving the downstream hydrological conditions. The YHDWP started to transfer water when the downstream flow was below a certain level. Figure 12 shows the changes in the number of days below the standard level at XT over different months during the post-impact and the transition periods. The number of days below $530 \mathrm{~m}^{3} / \mathrm{s}$ from November to March was reduced from 88 to 51 days, decreased by $42 \%$, the number of days below $600 \mathrm{~m}^{3} / \mathrm{s}$ from April to October was reduced from 99 to 32 days, decreasing by $68 \%$, and the number of days below $800 \mathrm{~m}^{3} / \mathrm{s}$ from May to September decreased from 157 to 78 days, decreasing by $68 \%$. The results further illustrate that the YHDWP has a significant improvement effect on the downstream hydrological conditions.

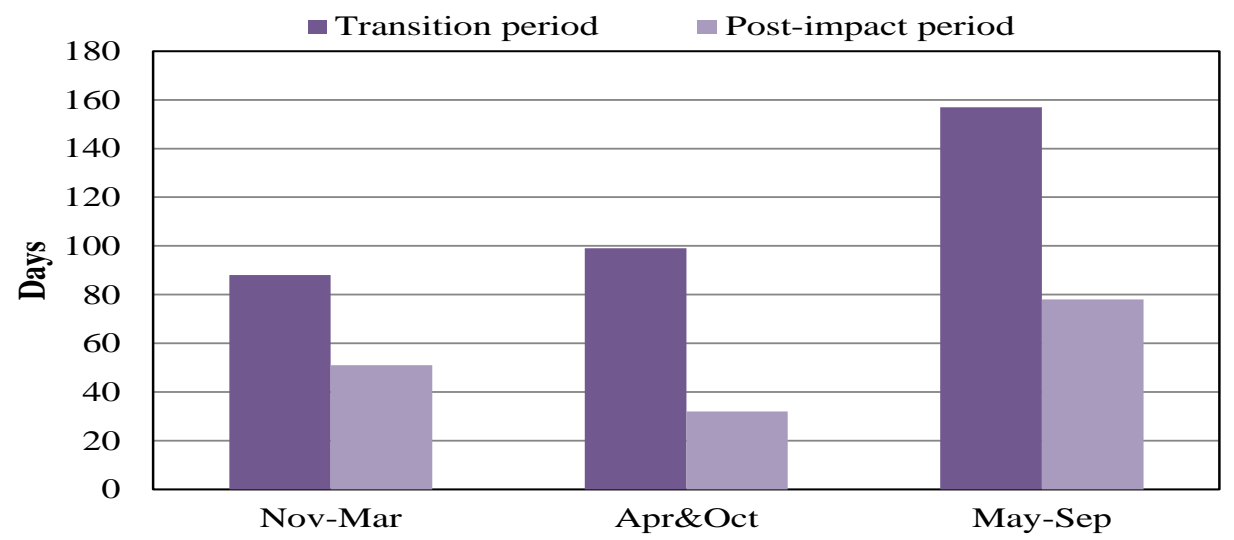

Figure 12. The number of days of low-standard streamflow in different months between the transition and post-impact periods. The standard streamflow from November to March is $530 \mathrm{~m}^{3} / \mathrm{s}$. The standard streamflow in April and October is $600 \mathrm{~m}^{3} / \mathrm{s}$. The standard streamflow from May to September is $800 \mathrm{~m}^{3} / \mathrm{s}$.

In the post-impact period, both maximum and minimum flow values of three stations decreased to some extent. The 1-day, 3-day, 7-day, 30-day and 90-day mimimum flow values decreased from 15\% to $30 \%$, and the maximum flow values decreased approximately by 20 to $40 \%$. In general, the reduction degree of the maximum flow value is greater than the minimum flow value, indicating that the MSNDWP has a more significant peak-shaving effect on the middle and lower Hanjiang River. 
Table 5. Changes of IHA metrics in the post-impact period.

\begin{tabular}{|c|c|c|c|c|c|c|c|c|c|}
\hline & \multicolumn{3}{|c|}{ Huangjiagang } & \multicolumn{3}{|c|}{ Huangzhuang } & \multicolumn{3}{|c|}{ Xiantao } \\
\hline & \multirow{2}{*}{$\begin{array}{c}\begin{array}{c}\text { Transition } \\
\text { Period } \\
(2000-2013)\end{array} \\
\text { Mean Value }\end{array}$} & \multicolumn{2}{|c|}{$\begin{array}{l}\text { Post-Impact Period } \\
\quad(2014-2018)\end{array}$} & \multirow{2}{*}{$\begin{array}{c}\begin{array}{c}\text { Transition } \\
\text { Period } \\
(2000-2013)\end{array} \\
\text { Mean Value }\end{array}$} & \multicolumn{2}{|c|}{$\begin{array}{l}\text { Post-Impact Period } \\
\text { (2014-2018) }\end{array}$} & \multirow{2}{*}{$\begin{array}{c}\begin{array}{c}\text { Transition } \\
\text { Period } \\
(2000-2013)\end{array} \\
\text { Mean Value }\end{array}$} & \multicolumn{2}{|c|}{$\begin{array}{l}\text { Post-Impact Period } \\
\text { (2014-2018) }\end{array}$} \\
\hline & & Mean Value & $\begin{array}{c}\text { Relative } \\
\text { Change (\%) }\end{array}$ & & Mean Value & $\begin{array}{c}\text { Relative } \\
\text { Change (\%) }\end{array}$ & & Mean Value & $\begin{array}{c}\text { Relative } \\
\text { Change (\%) }\end{array}$ \\
\hline \multicolumn{10}{|l|}{ Group 1: Mean Flow } \\
\hline January & 737.20 & 539.40 & -26.83 & 866.80 & 697.30 & -19.55 & 814.40 & 611.80 & -24.88 \\
\hline February & 741.80 & 566.30 & -23.66 & 838.20 & 686.60 & -18.09 & 796.10 & 625.40 & -21.44 \\
\hline March & 764.40 & 556.30 & -27.22 & 878.10 & 722.00 & -17.78 & 837.50 & 671.30 & -19.84 \\
\hline April & 827.20 & 704.70 & -14.81 & 917.40 & 959.90 & 4.63 & 820.80 & 857.20 & 4.43 \\
\hline May & 890.00 & 838.20 & -5.82 & 1038.00 & 1130.00 & 8.86 & 916.70 & 1006.00 & 9.74 \\
\hline June & 940.90 & 1018.00 & 8.19 & 1197.00 & 1362.00 & 13.78 & 1012.00 & 1145.00 & 13.14 \\
\hline July & 1450.00 & 983.20 & -32.19 & 2282.00 & 1375.00 & -39.75 & 1781.00 & 1251.00 & -29.76 \\
\hline August & 1630.00 & 678.00 & -58.40 & 2584.00 & 1063.00 & -58.86 & 1954.00 & 902.30 & -53.82 \\
\hline September & 1854.00 & 697.10 & -62.40 & 2524.00 & 987.00 & -60.90 & 2035.00 & 815.80 & -59.91 \\
\hline October & 1171.00 & 1221.00 & 4.27 & 1526.00 & 1923.00 & 26.02 & 1288.00 & 1704.00 & 32.30 \\
\hline November & 788.80 & 547.50 & -30.59 & 1016.00 & 812.20 & -20.06 & 928.60 & 776.40 & -16.39 \\
\hline December & 756.80 & 527.30 & -30.33 & 887.80 & 704.00 & -20.70 & 814.60 & 635.40 & -22.00 \\
\hline \multicolumn{10}{|c|}{ Group 2: Annual Extreme } \\
\hline 1-day minimum & 425.10 & 355.10 & -16.47 & 519.50 & 444.90 & -14.36 & 475.10 & 397.70 & -16.29 \\
\hline 3-day minimum & 453.00 & 367.20 & -18.94 & 542.20 & 452.50 & -16.54 & 487.90 & 407.00 & -16.58 \\
\hline 7-day minimum & 478.40 & 378.60 & -20.86 & 563.10 & 477.50 & -15.20 & 508.90 & 416.60 & -18.14 \\
\hline 30-day minimum & 540.40 & 398.40 & -26.28 & 627.00 & 524.50 & -16.35 & 568.20 & 473.10 & -16.74 \\
\hline 90-day minimum & 609.00 & 438.40 & -28.01 & 701.30 & 565.20 & -19.41 & 627.10 & 535.90 & -14.54 \\
\hline 1-day maximum & 4998.00 & 2857.00 & -42.84 & 7584.00 & 5116.00 & -32.54 & 5102.00 & 3808.00 & -25.36 \\
\hline 3-day maximum & 4770.00 & 2748.00 & -42.39 & 7050.00 & 4722.00 & -33.02 & 4916.00 & 3647.00 & -25.81 \\
\hline 7-day maximum & 4285.00 & 2622.00 & -38.81 & 5958.00 & 4043.00 & -32.14 & 4332.00 & 3312.00 & -23.55 \\
\hline 30-day maximum & 2632.00 & 1999.00 & -24.05 & 3795.00 & 2956.00 & -22.11 & 2925.00 & 2532.00 & -13.44 \\
\hline 90-day maximum & 1872.00 & 1312.00 & -29.91 & 2683.00 & 1943.00 & -27.58 & 2138.00 & 1682.00 & -21.33 \\
\hline
\end{tabular}


Table 5. Cont.

\begin{tabular}{|c|c|c|c|c|c|c|c|c|c|}
\hline & \multicolumn{3}{|c|}{ Huangjiagang } & \multicolumn{3}{|c|}{ Huangzhuang } & \multicolumn{3}{|c|}{ Xiantao } \\
\hline & \multirow{2}{*}{$\begin{array}{c}\begin{array}{c}\text { Transition } \\
\text { Period } \\
(2000-2013)\end{array} \\
\text { Mean Value }\end{array}$} & \multicolumn{2}{|c|}{$\begin{array}{l}\text { Post-Impact Period } \\
\text { (2014-2018) }\end{array}$} & \multirow{2}{*}{$\begin{array}{c}\begin{array}{c}\text { Transition } \\
\text { Period } \\
(2000-2013)\end{array} \\
\text { Mean Value }\end{array}$} & \multicolumn{2}{|c|}{$\begin{array}{l}\text { Post-Impact Period } \\
\text { (2014-2018) }\end{array}$} & \multirow{2}{*}{$\begin{array}{c}\begin{array}{c}\text { Transition } \\
\text { Period } \\
(2000-2013)\end{array} \\
\text { Mean Value }\end{array}$} & \multicolumn{2}{|c|}{$\begin{array}{l}\text { Post-Impact Period } \\
\quad(2014-2018)\end{array}$} \\
\hline & & Mean Value & $\begin{array}{c}\text { Relative } \\
\text { Change (\%) }\end{array}$ & & Mean Value & $\begin{array}{c}\text { Relative } \\
\text { Change (\%) }\end{array}$ & & Mean Value & $\begin{array}{c}\text { Relative } \\
\text { Change (\%) }\end{array}$ \\
\hline \multicolumn{10}{|c|}{ Group 3: Timing of Extreme } \\
\hline Number of zero days & 0.00 & 0.00 & - & 0.00 & 0.00 & - & 0.00 & 0.00 & - \\
\hline Base flow index & 0.47 & 0.54 & 14.56 & 0.43 & 0.48 & 11.71 & 0.45 & 0.45 & -0.31 \\
\hline Date of minimum & 200.36 & 142.20 & -29.03 & 193.21 & 251.80 & 30.32 & 144.50 & 201.20 & 39.24 \\
\hline Date of maximum & 210.50 & 240.00 & 14.01 & 213.93 & 226.20 & 5.74 & 215.43 & 227.60 & 5.65 \\
\hline \multicolumn{10}{|c|}{ Group 4: Frequency and Duration } \\
\hline Low pulse count & 1.64 & 6.60 & 301.70 & 3.00 & 8.40 & 180.00 & 0.00 & 0.20 & - \\
\hline Low pulse duration & 9.45 & 5.17 & -45.30 & 10.72 & 4.18 & -61.05 & - & 3.00 & - \\
\hline High pulse count & 1.21 & 0.40 & -67.05 & 2.29 & 0.60 & -73.75 & 2.36 & 1.20 & -49.09 \\
\hline High pulse duration & 9.14 & 10.00 & 9.42 & 8.23 & 13.00 & 58.05 & 10.48 & 8.83 & -15.72 \\
\hline \multicolumn{10}{|l|}{ Group 5: Rate } \\
\hline Rise rate & 96.35 & 49.95 & -48.16 & 148.40 & 95.93 & -35.36 & 89.76 & 52.62 & -41.38 \\
\hline Fall rate & 97.57 & 49.70 & -49.06 & 120.00 & 76.63 & -36.14 & 69.81 & 44.96 & -35.60 \\
\hline Number of reversals & 194.60 & 193.60 & -0.51 & 152.50 & 136.20 & -10.69 & 101.90 & 106.20 & 4.22 \\
\hline
\end{tabular}

Note: The number in bold indicate relative change greater than $10 \%$. 
The scheduling rules of DJK were changed on account of the operation of the MSNDWP. The date of minimum flow value at HJG was extended by 58 days, while the date of minimum flow value at HZ and XT was delayed by 59 and 56 days, respectively. The date of maximum flow value of three stations was stable at about 230th day. The low pulse count at HJG and HZ increased by 5 and 5.4, and the low pulse duration decreased by 4.3 days and 6.5 days, respectively. Low flow pulse appeared for the first time at XT in the post-impact period, whereas the values were far less than those at HJG and HZ, indicating that compensation projects, especially YHDWP, played a positive role in downstream of Hanjiang River. The high pulse count further decreased in three stations, which almost disappeared in the middle and lower Hanjiang River. The rise and fall rates of the stations decreased from $35 \%$ to $50 \%$, and the number of reversals had inapparent change.

The operation of the MSNWDP benefited more than 60 million people in Henan Province, Hebei Province, Tianjin Province, and Beijing City of China, solving water scarcity and the living conditions of a large number of cities along the route, more than 30 billion $\mathrm{m}^{3}$ of water has been transferred for five northern provinces and cities by the end of 2019. The MSNWDP have an important role in restoring the groundwater level of the North China Plain, the water diverted from DJK to Beijing City reduced cumulative groundwater depletion by almost $3.6 \mathrm{~km}^{3}$, accounting for $40 \%$ of groundwater recovery in recent years [38]. On the other hand, the water transfer project brought certain problems to the middle and lower Hanjiang River, as well. For example, a reduction water level caused by the significant reduction of runoff, making water catchment along the river difficult. However, many compensation projects, such as the YHDWP, have alleviated the damage to hydrological conditions, navigation, and ecological environment in downstream Hanjiang River.

\section{Conclusions}

The long-series daily streamflow data obtained from three stations were used to analyze the changes and trends of IHA indicators and eco-flow indicators, in order to study the impact of the implementation of multi-projects on the hydrological conditions of the middle and lower Hanjiang River. The operation of the DJK resulted in a decrease in the annual streamflow in the upstream HJG, while the annual average streamflow was not changed significantly in the middle and downstream stations, although the fluctuations were concentrated within a range. The construction of cascade reservoirs reduced annual streamflow significantly at $\mathrm{HZ}$ and XT. The completion of the MSNDWP led to a decrease in the annual average streamflow at three stations that was greater than the impact caused by the finalization of the Danjiangkou Reservoir.

The eco-flow indicators show that the construction of DJK has a positive effect on the ecological status of downstream, while cascade reservoirs have no direct impact, and the operation of the MSNDWP could damage the river ecology. The analysis of the IHA index shows a significant increase in the monthly discharge, and prominently due to the DJK in the downstream stations during the dry season, while it decreased during the wet season. Additionally, the minimum flow value, and the number of reversals increased; the maximum flow value, the low pulse duration, and the rates of rise and fall significantly decreased. Various indicators decreased slightly in downstream stations affected by the cascade reservoir. Moreover, the reduction of the runoff caused by the MSNDWP was higher from July to September during the wet season, than during the dry season. Compensation projects such as YHDWP alleviate the reduction of the discharge downstream from July to September. The maximum and minimum flow values, low pulse duration, and the rates of rise and fall were all reduced; the high pulse almost disappeared.

This study analyzed the impact of various water resources development and use projects on the natural flow regime of the middle and lower Hanjiang River during the past 60 years. On the one hand, the changes in the hydrological conditions negatively affected the river ecosystem, especially in the number of floating fish communities. On the other hand, water resources were better exploited and used through the construction of engineering infrastructures, which involve very significant functions such as hydropower generation, irrigation, navigation, flood control, or for combating 
drought. This research contributes to achieving a better understanding of the benefits of a joint operation between DJK and cascade reservoirs, which may entail better management of water resources finding a balance between economic and environmental sustainability.

The MSNDWP has operated over a short period, and as the volume of water transfer increases gradually, the impact on the middle and lower Hanjiang River still needs further attention. The benchmarking framework of this study can serve as a point of reference for the evaluation of possible impacts and countermeasures when new infrastructures are built in the future such as Xinji Reservoir, Yakou Reservoir, and Nianpanshan Reservoir.

Author Contributions: Data curation, X.Y.; Supervision, J.Z. and J.C.; Validation, J.Z. and J.C.; Writing - review \& editing, X.Y. All authors have read and agreed to the published version of the manuscript.

Funding: This work was partly supported by grants from the National Key Research and Development Program of China (2018YFC0406505) and National Natural Science of China (51779176).

Conflicts of Interest: The authors declare no conflict of interest.

\section{References}

1. Poff, L.R.; Zimmerman, J.K.H. Ecological responses to altered flow regimes: A literature review to inform the science and management of environmental flows. Freshw. Biol. 2010, 55, 194-205. [CrossRef]

2. Poff, N.L.; Allan, J.D.; Bain, M.B.; Karr, J.R.; Prestegaard, K.L.; Richter, B.D.; Sparks, R.E.; Stromberg, J.C. The Natural Flow Regime. BioScience 1997, 47, 769-784. [CrossRef]

3. Magilligan, F.J.; Nislow, K.H. Changes in hydrologic regime by dams. Geomorphology 2005, 71, 61-78. [CrossRef]

4. Brath, A.; Montanari, A.; Moretti, G. Assessing the effect on flood frequency of land use change via hydrological simulation (with uncertainty). J. Hydrol. 2006, 324, 141-153. [CrossRef]

5. Li, Q.; Yu, M.; Lu, G.; Cai, T.; Xue, B.; Xia, Z. Impacts of the Gezhouba and Three Gorges reservoirs on the sediment regime in the Yangtze River, China. J. Hydrol. 2011, 403, 224-233. [CrossRef]

6. Rolls, R.J.; Growns, I.O.; Khan, T.A.; Wilson, G.G.; Ellison, T.L.; Prior, A.; Waring, C.C. Fish recruitment in rivers with modified discharge depends on the interacting effects of flow and thermal regimes. Freshw. Biol. 2013, 58, 1804-1819. [CrossRef]

7. Zhang, Q.; Xu, C.Y.; Becker, S.; Jiang, T. Sediment and runoff changes in the Yangtze River basin during past 50 years. J. Hydrol. 2006, 331, 511-523. [CrossRef]

8. Rosenberg, D.M.; Mccully, P.; Pringle, C.M. Global-Scale Environmental Effects of Hydrological Alterations: Introduction. Bioscience 2000, 50, 746-751. [CrossRef]

9. Biggs, B.J.F.; Nikora, V.I.; Snelder, T.H. Linking scales of flow variability to lotic ecosystem structure and function. River Res. Appl. 2005, 21, 283-298. [CrossRef]

10. Olden, J.D.; Naiman, R.J. Incorporating thermal regimes into environmental flows assessments: Modifying dam operations to restore freshwater ecosystem integrity. Freshw. Biol. 2010, 55, 86-107. [CrossRef]

11. Campisano, A.; Creaco, E.; Modica, C. Numerical modelling of sediment bed aggradation in open rectangular drainage channels. Urban Water J. 2013, 10, 365-376. [CrossRef]

12. Christer, N.; Reidy, C.A.; Mats, D.; Carmen, R. Fragmentation and flow regulation of the world's large river systems. Science 2005, 308, 405-408.

13. Poff, N.L.; Matthews, J.H. Environmental flows in the Anthropocence: Past progress and future prospects. Curr. Opin. Environ. Sustain. 2013, 5, 667-675. [CrossRef]

14. Caiola, N.; Ibáñez, C.; Verdú, J.; Munné, A. Effects of flow regulation on the establishment of alien fish species: A community structure approach to biological validation of environmental flows. Ecol. Indic. 2014, 45, 598-604. [CrossRef]

15. Castello, L.; Macedo, M.N. Large-scale degradation of Amazonian freshwater ecosystems. Glob. Chang. Biol. 2016, 22, 990-1007. [CrossRef]

16. Gao, B.; Yang, D.; Zhao, T.; Yang, H. Changes in the eco-flow metrics of the Upper Yangtze River from 1961 to 2008. J. Hydrol. 2012, 448-449, 30-38. [CrossRef] 
17. Wang, Y.; Rhoads, B.L.; Wang, D. Assessment of the flow regime alterations in the middle reach of the Yangtze River associated with dam construction: Potential ecological implications. Hydrol. Process. 2016, 30, 3949-3966. [CrossRef]

18. Li, D.; Di, L.; Zhao, J.; Hui, L.; Yang, H. Observed changes in flow regimes in the Mekong River basin. J. Hydrol. 2017, 551, 217-232. [CrossRef]

19. Richter, B.D.; Baumgartner, J.V.; Powell, J.; Braun, D.P. A Method for Assessing Hydrologic Alteration within Ecosystems. Conserv. Biol. 1996, 10, 1163-1174. [CrossRef]

20. Richter, B.D.; Baumgartner, J.V.; Braun, D.P.; Powell, J. A spatial assessment of hydrologic alteration within a river network. Regul. Rivers Res. Manag. 1998, 14, 329-340. [CrossRef]

21. Gao, Y.; Vogel, R.M.; Kroll, C.N.; Poff, N.L.; Olden, J.D. Development of representative indicators of hydrologic alteration. J. Hydrol. 2009, 374, 136-147. [CrossRef]

22. Peres, D.J.; Cancelliere, A. Environmental Flow Assessment Based on Different Metrics of Hydrological Alteration. Water Resour. Manag. 2017, 30,1-19. [CrossRef]

23. Li, D.; Wan, W.; Zhao, J. Optimizing environmental flow operations based on explicit quantification of IHA parameters. J. Hydrol. 2018, 563, 510-522. [CrossRef]

24. Richter, B.; Baumgartner, J.; Wigington, R.; Braun, D. How much water does a river need? Freshw. Biol. 1997, 37, 231-249. [CrossRef]

25. Cochrane, T.A.; Arias, M.E.; Piman, T. Historical impact of water infrastructure on water levels of the Mekong River and the Tonle Sap system. Hydrol. Earth Syst. Sci. 2014, 18, 4529-4541. [CrossRef]

26. Jackson, R.B.; Carpenter, S.R.; Dahm, C.N.; McKnight, D.M.; Naiman, R.J.; Postel, S.L.; Running, S.W. Water in a changing world. Ecol. Appl. 2001, 11, 1027-1045. [CrossRef]

27. Postel, S.L.; Daily, G.C.; Ehrlich, P.R. Human appropriation of renewable fresh water. Science 1996, 271, 785-788. [CrossRef]

28. Lu, W.; Lei, H.; Yang, D.; Tang, L.; Miao, Q. Quantifying the impacts of small dam construction on hydrological alterations in the Jiulong River basin of Southeast China. J. Hydrol. 2018, 567, 382-392. [CrossRef]

29. Zhang, Q.; Zhang, Z.; Shi, P.; Singh, V.P.; Gu, X. Evaluation of ecological instream flow considering hydrological alterations in the Yellow River basin, China. Glob. Planet. Chang. 2018, 160, 61-74. [CrossRef]

30. Yang, S.L.; Milliman, J.D.; Li, P.; Xu, K. 50,000 dams later: Erosion of the Yangtze River and its delta. Glob. Planet. Chang. 2011, 75, 14-20. [CrossRef]

31. Wang, Y.; Wang, D.; Wu, J. Assessing the impact of Danjiangkou reservoir on ecohydrological conditions in Hanjiang river, China. Ecol. Eng. 2015, 81, 41-52. [CrossRef]

32. Chen, D.; Hu, M.; Wang, J.; Guo, Y.; Dahlgren, R.A. Factors controlling phosphorus export from agricultural/forest and residential systems to rivers in eastern China, 1980-2011. J. Hydrol. 2016, 533, 53-61. [CrossRef]

33. Ma, Z.; Kang, S.; Zhang, L.; Tong, L.; Su, X. Analysis of impacts of climate variability and human activity on streamflow for a river basin in arid region of northwest China. J. Hydrol. 2008, 352, 239-249. [CrossRef]

34. Gocic, M.; Trajkovic, S. Analysis of changes in meteorological variables using Mann-Kendall and Sen's slope estimator statistical tests in Serbia. Glob. Planet. Chang. 2013, 100, 172-1872. [CrossRef]

35. Vogel, R.M.; Sieber, J.; Archfield, S.A.; Smith, M.P.; Apse, C.D.; Huber-Lee, A. Relations among storage, yield, and instream flow. Water Resour. Res. 2007, 43. [CrossRef]

36. Vogel, R.M.; Member, J.; Fennessey, N. Flow-Duration Curves. I: New Interpretation and Confidence Intervals. J. Water Resour. Plan. Manag. 1994, 120, 485-504. [CrossRef]

37. Vogel, R.M.; Fennessey, N. Flow duration curves II: A review of applications in water resources planning. J. Am. Water Resour. Assoc. 1995, 31, 1029-1039. [CrossRef]

38. Long, D.; Yang, W.; Scanlon, B.R.; Zhao, J.; Liu, D.; Burek, P.; Pan, Y.; You, L.; Wada, Y. South-to-North Water Diversion stabilizing Beijing's groundwater levels. Nat. Commun. 2020, 11, 3665. [CrossRef]

(C) 2020 by the authors. Licensee MDPI, Basel, Switzerland. This article is an open access article distributed under the terms and conditions of the Creative Commons Attribution (CC BY) license (http://creativecommons.org/licenses/by/4.0/). 